\title{
Fair pricing of REDD-based emission offsets under risk preferences and benefit-sharing
}

\author{
Andrey Krasovskii ${ }^{\mathrm{a}, *}$, Nikolay Khabarov ${ }^{\mathrm{a}}$, Michael Obersteiner ${ }^{\mathrm{a}}$ \\ ${ }^{a}$ International Institute for Applied Systems Analysis (IIASA) \\ Schlossplatz 1, A-2361, Laxenburg, Austria
}

\begin{abstract}
We consider a risk-aware forest owner and electricity producer evaluating the Reduced Emissions from Deforestation and Degradation (REDD)-based offsets with a benefit-sharing mechanism under uncertain $\mathrm{CO}_{2}$ prices. For a range of $\mathrm{CO}_{2}$ prices and respective risks perceived by the forest owner (seller) and electricity producer (buyer), we apply a model of fair (indifference) pricing. Parties' risk preferences are reflected by exponential utility functions. The potentially contracted amounts of REDD offsets are analyzed under various risk preferences and for different benefit-sharing opportunities. Our results show that a risk-averse attitude considerably increases the contracted offset amounts (compared to risk-neutral case) and, therefore, creates a higher potential for REDD implementation. We demonstrate possible situations, when parties could agree on a certain range of REDD contracts, e.g. smaller amounts of REDD offsets are traded for higher prices, and larger amounts - for lower prices, although contracting a moderate amount at a moderate price is impossible. The suggested benefit-sharing mechanism can help increase contracted offset amounts. Our modeling results highlight two ways to promote higher REDD participation: (i) strengthening the carbon price signal to reveal risk-averse behavior of energy producers, and (ii) implementing the mechanism of benefit/risk sharing between the REDD consumer and supplier.
\end{abstract}

Keywords: electricity generation, $\mathrm{CO}_{2}$ emissions, REDD offsets, benefit-sharing, risk preferences

\footnotetext{
${ }^{*}$ Corresponding author

Email address: krasov@iiasa.ac.at (Andrey Krasovskii)
} 


\section{Introduction}

This paper elaborates on the development of financial instruments that support Reduced Emissions from Deforestation and Degradation (REDD) (Lubowski and Rose, 2013; Obersteiner et al., 2009; Krasovskii et al., 2014). In the papers Fuss et al. (2011); Szolgayová et al. (2014) decision-making of the price-taking electricity producers consists of choosing between investing in research and development (R\&D) to implement new technologies (carbon capture and storage (CCS) modules) and buying REDD options. We explore a similar idea of employing REDD for offsetting emissions of electricity producers by setting a new problem with a few distinctive features. Firstly, we consider the case when an energy producer has a market power (Stoft, 2002; Hunt and Evans, 2009; Janssen and Wobben, 2009) - the ability to reduce production output and charge higher electricity prices to consumers. Thus, in the face of uncertain $\mathrm{CO}_{2}$ prices the electricity producer with market power has more flexibility compared to the price-taking energy producer. Secondly, the electricity producer in our model is a medium-term decision maker: they do not change their technology portfolio by decommissioning $\mathrm{CO}_{2}$-intensive plants and building new power plants (which would be a long-term investment). The optimization model works with two time steps: initial (low) $\mathrm{CO}_{2}$ price and future (uncertain) $\mathrm{CO}_{2}$ price. This simplified rather conceptual modeling approach is justified, because a dynamic model would require additional information about the future which is not available at the moment: $\mathrm{CO}_{2}$ price formation process, REDD offsets acceptance on the market, etc. For the same reason we focus on the direct contracting of REDD offsets between the forest owner and electricity producer, and do not consider market modeling.

We construct a microeconomic model of interaction between the forest owner (REDD supplier), electricity producer (REDD offsets consumer), and electricity consumer. In the proposed partial equilibrium modeling framework $\mathrm{CO}_{2}$ prices are exogenous and uncertain. The decision-making process of the electricity producer (under a condition of an existing or absent $\mathrm{CO}_{2}$ tax/price) consists of (see, e.g., Stoft (2002); Masters (2004)): (i) choosing power plant load factors to minimize the cost given the hourly electricity demand profile and installed capacities of particular power generation tech-

nologies; and (ii) choosing an electricity price to maximize the profit based on 
the demand function indicating consumers' sensitivity to electricity prices. In the study we apply a constant elasticity demand function (Bohi, 2013).

The elevating $\mathrm{CO}_{2}$ price might impact not only the profits of the electricity producer (decrease), but also the electricity prices for the consumer (increase), and, hence, some financial instruments might be implemented today in order to be prepared for the uncertain $\mathrm{CO}_{2}$ prices in the future (Krasovskii et al., 2014). We propose and explore financial instruments supporting the REDD program. On the supply side of the REDD-based emission offsets we model a forest owner who decided to preserve the forest and sell respectively generated REDD-based emission offsets (further - REDD offsets). The focus of our analysis is on how the forest owner and the electricity producer evaluate their fair prices for different amounts of REDD offsets. In the paper the "fairness" of the price is understood in the sense of parties' indifference regarding whether to engage in contracting a given amount of REDD offsets or not. The fair price of the electricity producer (forest owner) means that for a higher (lower) price the electricity producer (forest owner) will not want to engage in the contract. In case the parties can agree on a fair price, the problem is to find a range of REDD offsets' amounts which can be contracted.

Risk preferences play an important role in the model of fair pricing. Here we employ exponential utility functions to reflect parties' risk attitudes. The exponential utility admits all types of risk preferences: risk-taking, riskneutral, and risk-averse.

The idea of benefit-sharing is important within the REDD context (Lindhjem et al., 2010). We propose a benefit-sharing mechanism that is activated in the case when electricity producer emits less than the amount of REDD offsets contracted in the first period (without $\mathrm{CO}_{2}$ price); in this case the unused amount of REDD offsets is shared with the forest owner.

The paper considers mathematical constructions and properties of a proposed financial instrument. Analytical results presented in the paper are illustrated by a numerical case study based on realistic data for regional electricity production. Modeling results show how risk preferences of the electricity producer and forest owner, combined with the benefit-sharing mechanism, impact the fair prices and contracted amounts of REDD offsets. Our key findings signal that higher REDD participation can be achieved when parties are risk-averse, and the benefit-sharing mechanism is activated. Risk preference is not a policy variable. However, the source of risks in our model is associated with uncertain $\mathrm{CO}_{2}$ tax/price distribution and REDD-offsets 
acceptance. Thus, to let the proposed mechanism work it is necessary to strengthen the relevant policy signal. A stronger $\mathrm{CO}_{2}$ price signal can reveal risk-averse behavior of energy producers.

\section{Modeling Framework}

In this section, firstly, we present a model of an electricity producer with market power operating without contracting REDD offsets. The decisionmaking of the electricity producer consists in choosing a technological mix in order to meet the hourly demand and to maximize profit. The optimal response in terms of emissions' reduction and raising electricity prices is constructed for any future $\mathrm{CO}_{2}$ price. Secondly, we introduce a two-period model for REDD offsets contracting. Given the distribution of uncertain $\mathrm{CO}_{2}$ prices in the second period, the electricity producer solves in the first period the problem of expected profit maximization for various amounts of contracted REDD offsets. In general, the electricity producer maximizes utility - a function of their profits. In our study we apply the exponential utility function, that fits well with our modeling framework. In the first time period, based on the comparison of maximum expected utilities with and without contracting REDD offsets, the electricity producer evaluates their fair (indifference) price for each amount of offsets that they could potentially buy. Similarly, the forest owner - the seller of REDD offsets - calculates their fair price, based on the exponential utility reflecting their risk preferences. We also introduce the benefit-sharing mechanism and solve the optimization problem of the electricity producer, who has two options: either (i) to emit more than available REDD offsets purchasing the $\mathrm{CO}_{2}$ offsets on the market to cover excess of their emissions, or (ii) to emit less and share the benefits from selling the excess of offsets at a market price with the forest owner.

In this study we develop the model proposed in Krasovskii et al. (2014). The model improvement consists of introducing utility functions and analysis of fair prices under exponential risk preferences. We also prove analytically results for risk-neutral utilities (a special case of exponential utility). This

extended version of the model allows for a wider application of benefit-sharing mechanism.

\subsection{Notations}

In our model the electricity producer uses $n$ technologies varying in costs (US\$/MWh, excluding emission costs) and emission factors (ton of $\mathrm{CO}_{2} / \mathrm{MWh}$ ). 
Let us introduce the following notations:

$a_{i}, i=1, . ., n$ are installed capacities (MW);

$v_{i}$ are variable costs (US\$/MWh);

$d_{j}, j=1, . ., 24$ is hourly average demand (MW);

$\boldsymbol{x}=\left\{x_{i j}\right\}, i=1 . ., n, j=1, . ., 24$, is a matrix of hourly load factors (controls, ratio between 0 and 1 );

$\boldsymbol{q}(\boldsymbol{x})=\left(q_{1}, ., q_{24}\right)=\left\{\sum_{i=1}^{n} a_{i} x_{i j}\right\}$ is a vector of hourly outputs (MW);

$Q=Q(\boldsymbol{x})=\sum_{i=1}^{n} a_{i} \sum_{j=1}^{2 \pi} x_{i j}$ is aggregate daily production (MWh);

$P^{e}$ is electricity price (US\$/MWh);

$D^{-1}: P^{e}=D^{-1}(Q)$ is inverse demand function (see Section 3.1);

$\varepsilon_{i}$ are emission factors (ton of $\mathrm{CO}_{2} / \mathrm{MWh}$ );

$p$ is $\mathrm{CO}_{2}$ price $\left(\mathrm{US} \$ /\right.$ ton of $\mathrm{CO}_{2}$ ).

\subsection{Model description}

For each matrix of load factors $\boldsymbol{x}$ the profit of the electricity producer in the absence of $\mathrm{CO}_{2}$ price is calculated as follows:

$$
\Pi_{e}(\boldsymbol{x})=R(\boldsymbol{x})-C(\boldsymbol{x})
$$

where

$$
R(\boldsymbol{x})=P^{e}(Q(\boldsymbol{x})) Q(\boldsymbol{x}),
$$

is the revenue, and

$$
C(\boldsymbol{x})=\sum_{i=1}^{N} v_{i} a_{i} \sum_{j=1}^{24} x_{i j}+F_{c}
$$

is the cost function. A constant fixed cost component, $F_{c}$, is not included in the optimization problem, and is used only for profit calculation.

For each $\mathrm{CO}_{2}$ price $p$ a production scenario $\boldsymbol{x}$ generates corresponding emissions:

$$
E(\boldsymbol{x})=\sum_{i=1}^{n} \varepsilon_{i} a_{i} \sum_{j=1}^{24} x_{i j},
$$

and the total profit of the electricity producer is calculated as follows:

$$
\Pi(\boldsymbol{x}, p)=\Pi_{e}(\boldsymbol{x})-E(\boldsymbol{x}) p .
$$

We will assume that the $\mathrm{CO}_{2}$ price belongs to a segment $p \in[0, \tilde{p}]$. Let us note that profit component $\Pi_{e}$ and emissions $E$ do not directly depend on 
price $p$, however, they are indirectly determined by the technological possibilities of the electricity producer.

We assume that hourly profile changes proportionally to the aggregate demand (see Krasovskii et al. (2014) and section 3.1 for details) and introduce the feasibility domain $\boldsymbol{X}$, which contains all technological mixes (controls) satisfying the hourly demand:

$$
\boldsymbol{X}=\left\{\boldsymbol{x}: x_{i j} \in[0,1] \text { and } \boldsymbol{q}(\boldsymbol{x}) \geq \frac{Q(\boldsymbol{x})}{Q^{0}} \boldsymbol{d}^{0}\right\},
$$

where $\boldsymbol{d}^{\mathbf{0}}=\left(d_{1}^{0}, . ., d_{24}^{0}\right)$ and $Q^{0}$ are, respectively, the initial hourly and daily aggregate demands (at zero $\mathrm{CO}_{2}$ price).

Remark 1. In the model we use hourly demand in order to allow for optimizing a technological mix with respect to exogenous $\mathrm{CO}_{2}$ prices. At the same time we model a market power based on the elasticity of aggregate demand. To reconcile these two dimensions, we introduced the proportionality assumption in the study. This assumption seems to be realistic; e.g. empirical analysis in Bigerna and Bollino (2013) indicates possible proportionality. ${ }^{1}$

For convenience, let us first consider the electricity producer as a profit maximizing decision maker, and afterwards introduce their utility (as a function of profit). The profit maximization problem is formulated as follows.

Problem 1 (without REDD offsets). Given the feasibility domain $\boldsymbol{X}$ (6), for every $\mathrm{CO}_{2}$ price $p$ the electricity producer maximizes their profit (5):

$$
\underset{\boldsymbol{x} \in \boldsymbol{X}}{\operatorname{maximize}} \Pi(\boldsymbol{x}, p) \text {. }
$$

Let us denote a solution to Problem 1 - the optimal technological mix by the symbol $\boldsymbol{x}_{\mathbf{1}}^{*}=\boldsymbol{x}_{\mathbf{1}}^{*}(p)$ for any price $p \in[0, \tilde{p}]$. Then, by definition of $\boldsymbol{x}_{\mathbf{1}}^{*}$ for any $\boldsymbol{x} \in \boldsymbol{X}(6)$ the following inequality holds:

$$
\Pi\left(\boldsymbol{x}_{1}^{*}, p\right) \geq \Pi(\boldsymbol{x}, p) .
$$

Let us denote by the symbol $\hat{\Pi}(p)$ the maximum profit at price $p$ :

$$
\hat{\Pi}(p)=\Pi\left(\boldsymbol{x}_{\mathbf{1}}^{*}(p), p\right)=\Pi_{e}\left(\boldsymbol{x}_{\mathbf{1}}^{*}(p)\right)-E\left(\boldsymbol{x}_{\mathbf{1}}^{*}(p)\right) p .
$$

The corresponding electricity price is calculated as $P^{e}\left(Q\left(\boldsymbol{x}_{\mathbf{1}}^{*}(p)\right)\right.$.

\footnotetext{
${ }^{1}$ see Bigerna and Bollino (2013), Figure 1 - Hourly profile of electricity demand in Italy - MWh, 2010-2011.
} 


\subsection{Assumptions for modeling}

In our study we assume the following properties of optimal profit $\hat{\Pi}(p)$ (9) and emissions $\hat{E}(p)=E\left(\boldsymbol{x}_{\mathbf{1}}^{*}(p)\right)$ with respect to $\mathrm{CO}_{2}$ price.

Assumption 1. The optimal profit and optimal emissions achieve their maxima at zero $\mathrm{CO}_{2}$ price, $p=0$, and are continuous strictly declining functions with respect to growing $p$ :

$$
\hat{\Pi}(p) \downarrow, \quad \hat{E}(p) \downarrow, \quad \text { when } \quad p \uparrow .
$$

This assumption is straightforward in the provided modeling framework as the power generation technologies are fixed (see also Krasovskii et al. (2014)). It is consistent with the results of larger scale modeling (OECD, 2009) in the short and medium term.

Remark 2. Under Assumption 1 for every $\mathrm{CO}_{2}$ price $p \in[0, \tilde{p}]$ there exists

a unique emissions level $\hat{E}(p)=E\left(\boldsymbol{x}_{\mathbf{1}}^{*}(p)\right)$ corresponding to maximum profit $\hat{\Pi}(p)$.

Remark 3. Assumption 1 basically restricts the consideration of electricity producers to those unfavorably (negatively) affected by an emerging $\mathrm{CO}_{2}$ price. Those who can potentially benefit from it, e.g. due to a competitive advantage, are not considered here. This situation is beyond the scope of this paper, which is focused on the problem of $\mathrm{CO}_{2}$-intensive power generation.

Based on Assumption 1 we prove the following lemma.

Lemma 1. For any $\boldsymbol{x} \in \boldsymbol{X}(6)$, such that $E(\boldsymbol{x}) \neq E\left(\boldsymbol{x}_{\mathbf{1}}^{*}(p)\right)$, the following inequality holds for all $p \in(0, \tilde{p}]$ :

$$
\Pi_{e}\left(\boldsymbol{x}_{\mathbf{1}}^{*}(p)\right)-E\left(\boldsymbol{x}_{\mathbf{1}}^{*}(p)\right) p>\Pi_{e}(\boldsymbol{x})-E(\boldsymbol{x}) p .
$$

The proof is given in Appendix A.

Lemma 1 has the following meaning. If we fix $\mathrm{CO}_{2}$ price $p$ and select an arbitrary mix of technologies $\boldsymbol{x}$ satisfying the hourly demand, such that the corresponding emissions differ from optimal emissions for the price $p$, then this mix $\boldsymbol{x}$ is not optimal for the electricity producer in the sense of profit maximization. 


\subsection{Modeling REDD-based offsets under uncertainty}

High $\mathrm{CO}_{2}$ price decreases the profit of the electricity producer. This negative effect as such can be amplified by uncertainty about the future $\mathrm{CO}_{2}$ price levels and lead to an excessive risk. To hedge against that the emitter can engage in contracting REDD offsets before the information about $\mathrm{CO}_{2}$ price is revealed, so that contracted REDD offsets could allow offsetting $\mathrm{CO}_{2}$ emissions in the future. Let us note that we are not taking into account additional factors in the payoff of a REDD supplier (forest owner), e.g. opportunity of deforesting and selling the wood. We assume that the forest owner decided to keep the forest for generating REDD offsets.

Let the future $\mathrm{CO}_{2}$ price be an uncertain variable (Raiffa, 1968) following a discrete probability distribution:

$$
\left\{p_{l}, w_{l}\right\}, \quad l=1, . ., m, \quad \sum_{l=1}^{m} w_{l}=1, \quad p_{l} \in[0, \tilde{p}], \quad w_{l} \in(0,1],
$$

where $w_{l}$ stands for probability, and realizations of possible prices are $p_{i} \neq p_{j}$, if $i \neq j$.

A problem is divided into two stages (time periods): in the first stage the forest owner and electricity producer negotiate an amount $\mathcal{E} \in\left(0, E^{0}\right]$ of REDD offsets and their price. Here $E^{0}$ is the maximum amount of emissions - generated by the electricity producer at zero $\mathrm{CO}_{2}$ price, i.e. $E^{0}=\hat{E}(0)$.

In the second stage they face the realization of uncertain $\mathrm{CO}_{2}$ prices. At each realization of the $\mathrm{CO}_{2}$ price the electricity producer can either use all REDD offsets (by emitting more or equal to the previously contracted amount $\mathcal{E}$ ), or emit less than $\mathcal{E}$ and share the benefit with the forest owner from selling the rest (unused offsets) on the market (at a market price $p$ ).

Benefit-sharing mechanism. The electricity producer and forest owner, when selling offsets on the market, get shares of the market price $\delta$ and $(1-\delta)$ respectively, so that:

- If $\delta=1$, the electricity producer has the right to sell the offsets in the second period at a market price without sharing the profit with forest owner.

- If $\delta=0$, the electricity producer can only use the contracted REDD credits to offset the factual amount of their emissions and the unused credits are returned (without compensation) back to the forest owner, 
i.e. no resale by the electricity producer is possible on the market. The profit from unused offsets goes entirely to the forest owner.

- If $0<\delta<1$, the electricity producer faces a trade-off between emitting more and, hence, using more of the contracted REDD credits for offsetting their emissions versus sharing the profit with the forest owner from selling the offsets at the market price.

The benefit-sharing ratio $\delta$ is included in the negotiation process between REDD-offsets supplier (forest owner) and consumer (electricity producer) along with the amount of offsets $\mathcal{E}$ and their price.

We assume that the forest owner and electricity producer face the same $\mathrm{CO}_{2}$ price distribution. The presence of REDD offsets at the second stage of the model leads to the following modification of the Problem 1 (the case without REDD).

Problem 2 (with REDD offsets). Given the feasibility domain $\boldsymbol{X}$ (6), $\mathrm{CO}_{2}$ price distribution $\left\{p_{l}, w_{l}\right\}$ (12), benefit-sharing ratio $\delta \in[0,1]$, and amount of $R E D D$ offsets $\mathcal{E} \in\left(0, E^{0}\right]$ contracted in the first time period the electricity producer solves in the second time period the following profit maximization problem for every possible future $\mathrm{CO}_{2}$ price $p_{l}$ :

$$
\underset{\boldsymbol{x} \in \boldsymbol{X}}{\operatorname{maximize}} \Pi^{R}\left(\boldsymbol{x}, p_{l}\right),
$$

where

$$
\Pi^{R}\left(\boldsymbol{x}, p_{l}\right)=\Pi_{e}(\boldsymbol{x})-p_{l}[E(\boldsymbol{x})-\mathcal{E}]_{+}+\delta p_{l}[\mathcal{E}-E(\boldsymbol{x})]_{+} .
$$

Here $[y]_{+}=\max \{y, 0\}$, meaning that the electricity producer can offset their emissions up to the amount $\mathcal{E}$ by using REDD offsets, the rest is sold on the market and the profit is shared with the forest owner.

The optimal technological mix $\boldsymbol{x}_{\mathbf{2}}^{*}\left(p_{l}\right)$ - solution to (13) - generates the maximum profit with REDD:

$$
\hat{\Pi}^{R}\left(p_{l}\right)=\Pi^{R}\left(\boldsymbol{x}_{\mathbf{2}}^{*}\left(p_{l}\right), p_{l}\right),
$$

at a particular $\mathrm{CO}_{2}$ price $p_{l}$. We denote by the symbol:

$$
E^{R}\left(p_{l}\right)=\left[\mathcal{E}-E\left(\boldsymbol{x}_{\mathbf{2}}^{*}\left(p_{l}\right)\right)\right]_{+},
$$

the corresponding amount of unused emission offsets that have to be sold on the market generating the profit (to be shared). 


\subsection{Modeling risk preferences of forest owner and electricity producer}

We model risk preferences by implementing utility functions. Let us denote by the symbol $U_{F}$ the utility of the forest owner, and by the symbol $U_{E}$ - electricity producer's utility. In our model utilities are functions of profits:

$$
U_{E}=U_{E}\left(\Pi_{E}\right), \quad U_{F}=U_{F}\left(\Pi_{F}\right) .
$$

Here symbol $\Pi_{F}$ stands for the profit of the forest owner from selling REDD offsets (to be specified in more detail in section 2.5.2), and $\Pi_{E}$ is the profit of electricity producer: $\Pi_{E}=\Pi$ as in (5) without REDD, and $\Pi_{E}=\Pi_{R}(14)$ with REDD. In this paper we deal with exponential utility functions. Thus, electricity producer's utility is given by the function:

$$
U_{E}\left(\Pi_{E}\right)=\left(1-e^{-\alpha \Pi_{E}}\right) / \alpha
$$

where $\alpha$ is a constant parameter that represents the degree of risk preference: $\alpha>0$ for risk aversion, and $\alpha<0$ for risk-taking. Applying L'Hôpital's rule, one can show the following asymptotic property:

$$
\lim _{\alpha \rightarrow 0} \frac{1-e^{-\alpha \Pi_{E}}}{\alpha}=\lim _{\alpha \rightarrow 0} \Pi_{E} e^{-\alpha \Pi_{E}}=\Pi_{E},
$$

meaning that when $\alpha$ tends to zero the utility function (18) converges to the risk-neutral utility $U_{E}\left(\Pi_{E}\right)=\Pi_{E}$. Exponential utility implies constant absolute risk aversion equal to $\alpha$ (see Pratt (1964)).

\subsubsection{Utility maximization by the electricity producer}

After the introduction of utility function (18) into the model, the profit maximization Problem 1 (without REDD) (7) and Problem 2 (with REDD) (13) can be substituted, respectively, by the utility maximization problems:

$$
\begin{array}{cc}
\underset{\boldsymbol{x} \in \boldsymbol{X}}{\operatorname{maximize}} & U_{E}\left(\Pi\left(\boldsymbol{x}, p_{l}\right)\right), \\
\underset{\boldsymbol{x} \in \boldsymbol{X}}{\operatorname{maximize}} & U_{E}\left(\Pi^{R}\left(\boldsymbol{x}, p_{l}\right)\right) .
\end{array}
$$

Remark 4. In the case of exponential utility function $U_{E}(18)$ the solutions to utility maximization problems (20) and (21) coincide with the solutions to the profit maximization problems (7) and (13), respectively. 
The utility function $U_{E}(18)$ is a strictly increasing with respect to $\Pi_{E}$ :

$$
\frac{d U_{E}}{d \Pi_{E}}=\frac{\alpha e^{-\alpha \Pi_{E}}}{\alpha}=e^{-\alpha \Pi_{E}}>0 .
$$

Let us consider the case without REDD: $\Pi_{E}=\Pi$ (5). The monotonicity property (22) by definition means that for all $\boldsymbol{x} \in \boldsymbol{X}$, such that $\Pi\left(\boldsymbol{x}_{1}^{*}, p_{l}\right) \geq$ $\Pi\left(\boldsymbol{x}, p_{l}\right)(8)$, we have

$$
U_{E}\left(\Pi\left(\boldsymbol{x}_{1}^{*}, p_{l}\right)\right) \geq U_{E}\left(\Pi\left(\boldsymbol{x}, p_{l}\right)\right),
$$

meaning that $\boldsymbol{x}_{1}^{*}\left(p_{l}\right)$ delivers the maximum $U_{E}\left(\hat{\Pi}\left(p_{l}\right)\right)$ in (20). The same reasoning is valid for the case with $\mathrm{REDD}$, implying that $\boldsymbol{x}_{2}^{*}\left(p_{l}\right)$ is the solution to problem (21).

\subsubsection{Utility of the forest owner}

The profit at price $p_{l}$ of the forest owner who does not contract REDD offsets in the first time period is calculated as follows:

$$
\Pi_{F}^{O}\left(p_{l}\right)=p_{l} \mathcal{E},
$$

meaning that they keep all the offsets in the first period and sells them in the second period when the $\mathrm{CO}_{2}$ price reveals.

Their profit when contracting REDD offsets in the first time period (under unknown $\mathrm{CO}_{2}$ price) is given by the optimal behavior (including benefitsharing) of the electricity producer (see Problem 2):

$$
\Pi_{F}^{R}\left(p_{l}\right)=(1-\delta) p_{l} E^{R}\left(p_{l}\right)+p_{F} \mathcal{E} .
$$

Recall, that symbol $E^{R}\left(p_{l}\right)=E^{R}(\mathcal{E}, \delta)(16)$ denotes emissions shared with the electricity producer in the second period at realization of $\mathrm{CO}_{2}$ price $p_{l}$. Here $p_{F}$ is the price of REDD offsets paid to the forest owner.

The utility function of the forest owner is given by the similar to (18) equation:

$$
U_{F}\left(\Pi_{F}\right)=\left(1-e^{-\beta \Pi_{F}}\right) / \beta,
$$

where $\beta$ is a constant representing the risk preferences. Here profit $\Pi_{F}=$ $\Pi_{F}^{O}$ (24) without REDD in the first time period, and $\Pi_{F}=\Pi_{F}^{R}$ (25) with contracting REDD offsets under uncertainty. 


\subsubsection{Expected utilities}

In order to determine fair prices we need to introduce expected utilities. Given the distribution $\left\{p_{l}, w_{l}\right\}(12)$ of $\mathrm{CO}_{2}$ price, they are calculated straightforward:

$$
\mathbb{E}\left[U_{E}\left(\Pi_{E}\right)\right]=\sum_{l=1}^{m} U_{E}\left(\Pi_{E}\left(p_{l}\right)\right) w_{l}, \quad \mathbb{E}\left[U_{F}\left(\Pi_{F}\right)\right]=\sum_{l=1}^{m} U_{F}\left(\Pi_{F}\left(p_{l}\right)\right) w_{l} .
$$

Remark 5. If we apply risk-neutral utilities (special cases of (18) when $\alpha \rightarrow$ 0 and (26) when $\beta \rightarrow 0$ ):

$$
U_{E}\left(\Pi_{E}\right)=\Pi_{E}, \quad U_{F}\left(\Pi_{F}\right)=\Pi_{F},
$$

then we arrive at the expected mean values (EMV) (Raiffa, 1968) in (27).

\subsubsection{Interpretation of risk preferences}

The interpretation of parameter $\alpha$ in (18) is the following. For illustration, let us consider a situation when a decision maker evaluates their participation in the lottery with two outcomes: they can win $10 \mathrm{mln}$. with a probability of 0.5 , or lose $10 \mathrm{mln}$. with the same probability. If $\alpha \simeq 0$, the decision maker's expected utility (27) is zero, meaning that they are indifferent regarding whether to participate in this lottery, or not. The risk-taker's expected utility (with $\alpha=-0.1$ ) is 5.43 , meaning that they are willing to participate in the lottery. On the contrary, the risk-averse decision maker $(\alpha=0.1)$ has an expected utility equal to -5.43 , meaning that they prefer to avoid this venture. In a similar manner, the risk preference parameters reflect parties' perception of the uncertain $\mathrm{CO}_{2}$ price distribution in our model.

In Figure 1 we can see the impact of risk preferences to the shape of an exponential utility function. Here we depict the functions of profit $U_{E}\left(\Pi_{E}\right)$ (18), where profit $\Pi_{E}$ belongs to the segment from 0 to 4 mln. US\$, determined by our case-study below.

\subsection{Fair prices in the model with exponential risk preferences}

The discussion below is devoted to valuation of various amounts of REDD offsets contracted in the first time period under unknown $\mathrm{CO}_{2}$ price assuming the given distribution (12) and a fixed benefit-sharing ratio $\delta \in[0,1]$. The forest owner and electricity producer evaluate their fair (indifference) prices

for the given amount of offsets. The electricity producer derives the price 


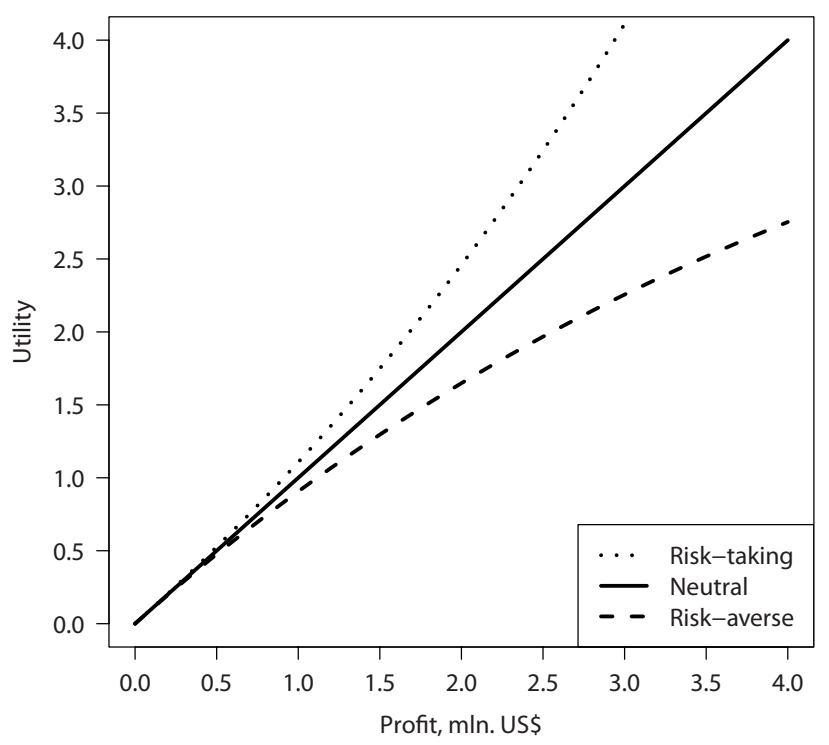

Figure 1: Sensitivity analysis of exponential utility function (18) with respect to risk preferences $\alpha=-0.2$ - risk-taking, $\alpha \simeq 0$ - risk-neutral, $\alpha=0.2$ - risk-averse.

they are willing to pay for the REDD offsets according to their indifference condition based on (9) and (15):

$$
\mathbb{E}\left[U_{E}\left(\hat{\Pi}\left(p_{l}\right)\right)\right]=\mathbb{E}\left[U_{E}\left(\hat{\Pi}^{R}\left(p_{l}\right)-p_{E} \mathcal{E}\right)\right] .
$$

Here $p_{E}$ is the desired fair price of the electricity producer. Let us note, that here we deal with the maximized expected utilities of the electricity producer. The maximum of the utility function's argument and, hence, the maximum of the utility function itself is achieved at solutions $\boldsymbol{x}_{2}^{*}\left(p_{l}\right)$ as the term $p_{E} \mathcal{E}$ is a constant and, hence, it is not included in the optimization (see (13), (20)-(21), and Remark 4). The indifference condition (29) means that electricity producer's expected utility stays the same regardless of whether or not the electricity producer participates in REDD.

Substituting exponential utility (18) into equality (29), we simplify it to the following equation with respect to unknown fair price $p_{E}$ :

$$
p_{E}=\frac{1}{\alpha \mathcal{E}}\left(\ln \left(\sum_{l=1}^{m} e^{-\alpha \hat{\Pi}\left(p_{l}\right)} w_{l}\right)-\ln \left(\sum_{l=1}^{m} e^{-\alpha \hat{\Pi}^{R}\left(p_{l}\right)} w_{l}\right)\right) .
$$

The indifference condition for the forest owner means that they choose their fair price $p_{F}$ in such a way, that their expected utility stays the same 
regardless of whether or not they engage in REDD in the first time period. Hence, the equation takes the form:

$$
\mathbb{E}\left[U_{F}\left(\Pi_{F}^{O}\left(p_{l}\right)\right)\right]=\mathbb{E}\left[U_{F}\left(\Pi_{F}^{R}\left(p_{l}\right)\right]\right.
$$

Let us derive the forest owner's fair price for REDD offsets by substituting (24)-(26) to (31):

$$
p_{F}=\frac{1}{\beta \mathcal{E}}\left(\ln \left(\sum_{l=1}^{m} e^{-\beta(1-\delta) p_{l} E^{R}\left(p_{l}\right)} w_{l}\right)-\ln \left(\sum_{l=1}^{m} e^{-\beta p_{l} \mathcal{E}} w_{l}\right)\right) .
$$

Thus, for the given $\mathrm{CO}_{2}$ price distribution $\left\{p_{l}, w_{l}\right\}, l=1, . ., m(12)$, benefit-sharing ratio $\delta \in[0,1]$ and amount of offsets $\mathcal{E} \in\left(0, E^{0}\right]$ one derives the fair prices of the forest owner $p_{F}$ (32) and the electricity producer $p_{E}(30)$. Using equations of the fair prices, we can find the volumes of REDD offsets $\mathcal{E}$, for which the deal takes place. Namely, the amount $\mathcal{E}$ can be contracted only if $p_{F}(\mathcal{E}) \leq p_{E}(\mathcal{E})$, meaning that the selling price $p_{F}$ is not higher than the buying price $p_{E}$. Functions $p_{F}=p_{F}(\mathcal{E})$ and $p_{E}=p_{E}(\mathcal{E})$ represent, respectively, risk-adjusted supply and demand curves for REDD offsets.

Remark 6. The exponential utility function (18) considered in this study possesses the feature of equal buying and selling price of an asset, discussed e.g. in Raiffa (1968).

If we consider an electricity producer having REDD offsets and wishing to sell them at a fair price denoted by $p_{E}^{s}$ subject to indifference equation inverse to (29):

$$
\mathbb{E}\left[U_{F}\left(\hat{\Pi}_{E}^{R}\left(p_{l}\right)\right)\right]=\mathbb{E}\left[U_{F}\left(\hat{\Pi}_{E}\left(p_{l}\right)+p_{E}^{s} \mathcal{E}\right)\right],
$$

we determine that the fair selling price coincides with the fair buying price: $p_{E}^{s}=p_{E}$ (30). The same is valid for the forest owner. It is well known that some other types of utilities do not possess this feature (see, e.g. Raiffa (1968), p. 90) ${ }^{2}$.

Defining fair prices (29), (31) allows for the application of a wide variety of utility functions. In Appendix B we show that for some functions the

\footnotetext{
${ }^{2}$ Let us note that Raiffa (1968) treats these prices as the prices for which one is willing to buy or sell their participation in the lottery. In our case "no lottery" means that the forest owner (electricity producer) does not participate in REDD.
} 
derivation of fair prices $p_{E}$ and $p_{F}$ may require additional numerical calculations.

To sum up, we apply exponential utility in this study for the following reasons:

1. It allows for modeling risk preferences by a single parameter

2. It contains a risk-neutral utility as a special case

3. The analytical derivation of fair prices is possible.

This form of utility is common in applied studies (see, e.g. Bocquého and Jacquet (2010); Lappi et al. (2010)).

\subsection{Analytical solution for risk-neutral case}

In the case of risk-neutral utilities (28) we analytically find solutions to utility maximization problems (20)-(21) of the electricity producer depending on the amount of REDD offsets $\mathcal{E} \in\left(0, E^{0}\right]$ and determine the corresponding fair prices of the forest owner and electricity producer. This allows us to obtain an analytical estimate of the amount of REDD offsets, that can be contracted.

Theorem 1 (Risk-neutral case). In the case, when both forest owner and electricity producer are risk-neutral, meaning that their expected utilities are mean values (28), for a given $\mathrm{CO}_{2}$ price distribution $\left\{p_{l}, w_{l}\right\}, l=1, . ., m$ (12) and for any benefit-sharing ratio $\delta \in[0,1)$ there exists an amount $\tilde{\mathcal{E}} \in\left(0, E^{0}\right]$ of REDD offsets up to which the fair prices of the forest owner $p_{F}$ (B.10) and of the electricity producer $p_{E}$ (B.6) coincide and are equal to the expected $\mathrm{CO}_{2}$ price $\bar{p}$. This amount equals the minimum optimal quantity of emissions generated by the electricity producer at the maximum possible $\mathrm{CO}_{2}$ price $\tilde{p}=$ $\max \left\{p_{l}\right\}$ :

$$
p_{F}=p_{E}=\bar{p} \quad \text { for any } \quad \mathcal{E} \leq \tilde{\mathcal{E}}, \quad \delta \in[0,1],
$$

where

$$
\tilde{\mathcal{E}}=E\left(\boldsymbol{x}_{\mathbf{1}}^{*}(\tilde{p})\right), \quad \bar{p}=\sum_{l=1}^{m} p_{l} w_{l} .
$$

For any amount of REDD offsets larger than $\tilde{\mathcal{E}}$ (35) the fair price of the forest owner $p_{F}$ is higher than the fair price of the electricity producer $p_{E}$ :

$$
p_{F}>p_{E} \quad \text { for any } \quad \mathcal{E}>\tilde{\mathcal{E}}, \quad \delta \in[0,1) .
$$

The proof is given in Appendix C. 
Remark 7. Theorem 1 shows that in the case of a bounded $\mathrm{CO}_{2}$ price distribution, the forest owner and electricity producer can contract any amount $\mathcal{E} \in(0, \tilde{\mathcal{E}}]$ of $R E D D$ offsets for the fair price $\bar{p}$. Thus, in the considered risk-neutral case, only two characteristics of distribution fully determine the solution to the problem: the mean and the highest price.

The practical consequence following from this result is that - on one hand - the potentially contracted amount is limited by the potentially high future $\mathrm{CO}_{2}$ price (the higher the price, the lower is the contracted amount). On the other hand, even in the risk-neutral case with possibility of a high $\mathrm{CO}_{2}$ price the contracted amount is non-zero, hinting at the opportunity to practically implement the REDD-based offset instrument featuring a benefitsharing approach as considered in this paper.

\section{Modeling Results}

The analytical solution obtained for the case of risk-neutral utilities (28) in the previous section is valid for a broad range of possible model setups in our modeling framework. In order to provide a numerical example and illustrate the impacts of risk preferences and benefit-sharing mechanism on the contracted amount of REDD offsets, we calibrate the model for a realistic case-study, and carry out numeric optimization.

\subsection{Data and calibration}

Technologies in the model. In our illustrative case study a regional electricity producer is operating power plants with the following technologies: coal (pulverized coal steam), combustion turbine (natural gas-fired) and combined cycle gas turbine (CCGT) (see Masters (2004)). The corresponding fixed and variable costs, as well as the installed capacities are given in Table 1 . The total size of installed capacity ( $7900 \mathrm{MW}$ ) is chosen to illustrate a model at a regional scale, and is roughly equivalent to the installed capacity of Belarus ${ }^{3}$.

Average hourly electricity demand. To construct an economically efficient production plan the electricity producer has to determine the combination of technologies to be used hourly during the day in order to satisfy the hourly

\footnotetext{
${ }^{3}$ See International Energy Statistics provided by the U.S. Energy Information Administration (EIA) http://www.eia.gov/cfapps/ipdbproject/
} 
Table 1: Technological data for the case-study. Sources: Masters (2004); Weisser (2007); Schröder et al. (2013).

\begin{tabular}{lllll}
\hline Technology & $\begin{array}{l}\text { Annual } \\
\text { fixed cost, } \\
\text { thou- } \\
\text { sands of } \\
\text { US\$/MWy }\end{array}$ & $\begin{array}{l}\text { Variable } \\
\text { US\$/MWh }\end{array}$ & $\begin{array}{l}\text { Installed } \\
\text { capacity, } \\
\mathrm{MW}\end{array}$ & $\begin{array}{l}\text { Emission } \\
\text { factors, } \\
\text { tons of } \\
\mathrm{CO}_{2} / \mathrm{MWh}\end{array}$ \\
\hline $\begin{array}{l}\text { Coal-fired } \\
224\end{array}$ & 18.9 & 3800 & 1.02 \\
\hline $\begin{array}{l}\text { Natural gas-fired } \\
\text { combustion tur- } \\
\text { bine }\end{array}$ & 64 & 55.6 & 1900 & 0.55 \\
\hline $\begin{array}{l}\text { Natural gas-fired } \\
\text { combined cycle }\end{array}$ & 96 & 39 & 2200 & 0.33 \\
\hline
\end{tabular}

demand profile. A hypothetical demand profile for an average day of the year is depicted in Figure 2. It features the same shape (peaks) as the regional profiles provided in the literature (Bigerna and Bollino, 2013; Andersen et al., 2013). The hourly demand values are scaled to match the installed capacity of the electricity producer (as in Table 1). Similar to Andersen et al. (2013) we use the hourly average demand for each day over a longer period, e.g. one year. We estimate the hourly profile change assuming that a change in aggregate demand leads to proportional shifts for every hour of the profile on an average day. Our model works with an average demand profile at the annual scale and provides a higher level of abstraction than the unit commitment (UC) problem (see, e.g. O'Neill et al. (2010)).

Demand function. We assume that the electricity producer has market power in the region, and use a constant elasticity demand curve, that is commonly employed in aggregate energy demand studies (Krishnamurthy and Kriström, 2015; Bohi, 2013). The consumers respond to the change in electricity price $P^{e}$ by changing the consumption $Q$ according to an aggregate demand function $D\left(P^{e}\right)$, i.e.,:

$$
P^{e}=D^{-1}(Q)=A Q^{\alpha},
$$

where $A>0$ is a constant, and $\alpha<0$ is the constant elasticity of demand. The coefficients of the aggregate demand function in our model are 


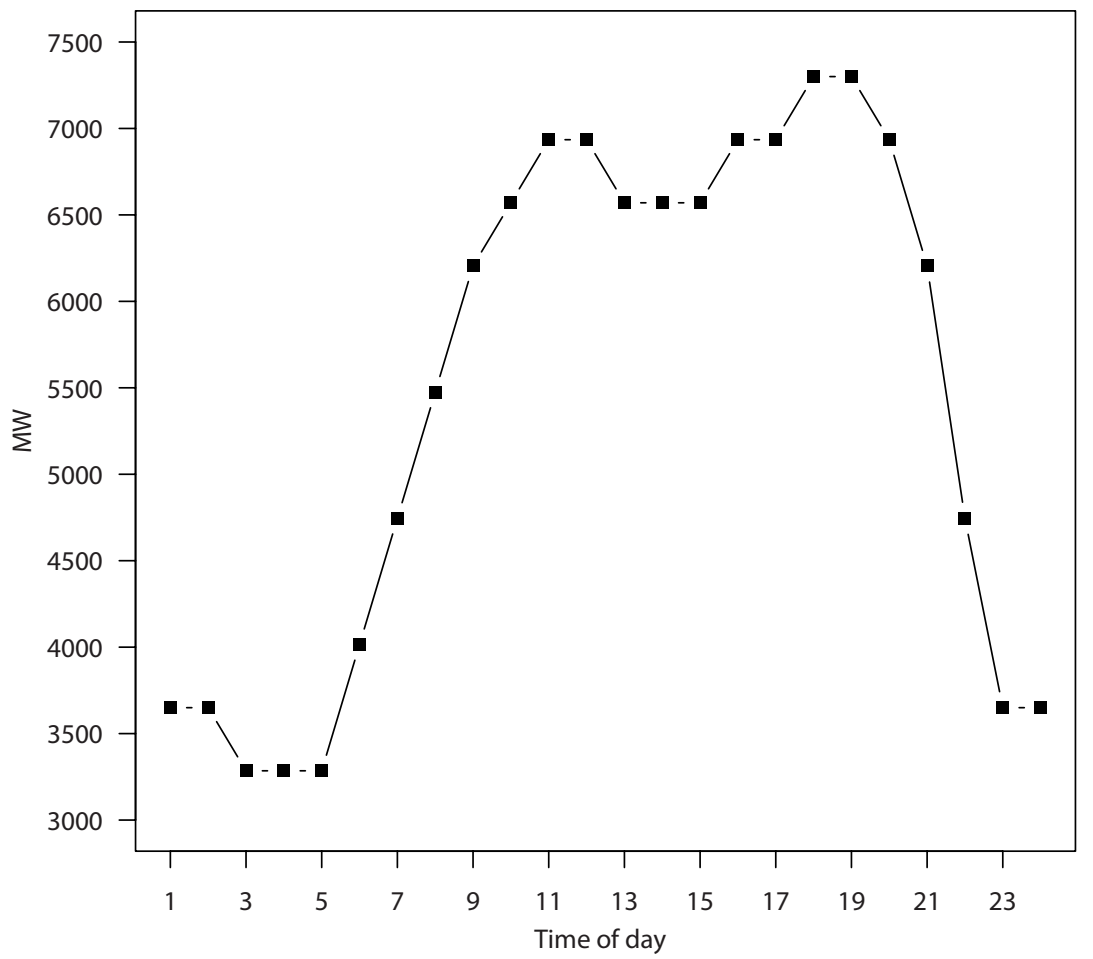

Figure 2: Average hourly electricity demand (based on Figure 1 in Bigerna and Bollino (2013)).

calibrated in such a way that a realistic electricity price (close to European ${ }^{4}$ electricity price) is achieved in the solution to an optimization Problem 1. The estimated parameters of the demand function (37) are $A=1.05 \times 10^{5}$, $\alpha=-0.612$. These values are consistent with $P^{e}=88.8 \mathrm{US} \$ / \mathrm{MWh}$ at maximum profit without $\mathrm{CO}_{2}$ price. The value of elasticity coefficient $\epsilon_{d}=$ $\frac{1}{\alpha}=-1.63$ is within a plausible range as estimated in the literature (for a set of OECD countries it was found to be within the confidence interval of $-2.3, \ldots,-0.1$, see, e.g. Krishnamurthy and Kriström (2015)). In our example the profit maximizing quantity is $Q^{0}=103.65 \mathrm{GWh} /$ day (which is approximately equal to the average daily electricity consumption in Belarus ${ }^{5}$ ),

\footnotetext{
${ }^{4}$ See Quarterly Reports On European Electricity Markets http://ec.europa.eu/energy/en/statistics/market-analysis

${ }^{5}$ See the EIA website: http://www.eia.gov/cfapps/ipdbproject/
} 
and the corresponding profit is $\hat{\Pi}\left(Q^{0}\right)=1.3 \mathrm{bln}$. US\$/year (excluding taxes and depreciation).

Emissions factors. For presently operating, coal-fired power plants the cumulative emissions range between 950 and $1250 \mathrm{gCO}_{2}$ eq/ $\mathrm{kWh}$ (Weisser, 2007). In our study we use a value from this interval as given in Table 1. Emissions factors for gas powered plants are taken from Schröder et al. (2013).

\subsection{Numerical results}

Simulations were carried out for the discrete (nine points) approximation of a uniform price distribution within the range 0-80 US\$/ton of $\mathrm{CO}_{2}$ :

$$
p_{l}=10(l-1), \quad w_{l}=\frac{1}{9}, \quad l=1, . ., 9 .
$$

Sizes of REDD-based offset contracts used in the model are within the range $\left[0, E^{0}\right]$, where $E^{0}$ is the optimal emission without $\mathrm{CO}_{2}$ price.

\subsubsection{A case of risk-neutral utilities}

Let us start with a case of risk-neutral utilities (28) (by setting parameters close to zero: $\alpha=0.001$ in (18), and $\beta=0.001$ in (26)). In Figure 3 the fair prices (30) and (32) with respect to the contracted amount of offsets $\mathcal{E} \leq E^{0}$ are depicted for the benefit-sharing ratio $\delta=0.5$. The plot demonstrates that the maximum amount of emissions offsets for which the deal can take place is $\tilde{\mathcal{E}}=E\left(\boldsymbol{x}^{*}\left(p_{9}\right)\right)=11.8 \mathrm{MtCO}_{2} /$ day, i.e. $4 \mathrm{GtCO}_{2} /$ year (at the equilibrium fair price $\bar{p}=40 \mathrm{US} \$ /$ ton $\left.\mathrm{CO}_{2}\right)$. That amount the electricity producer emits at the maximum $\mathrm{CO}_{2}$ price $p_{9}=80 \mathrm{US} \$ /$ ton $\mathrm{CO}_{2}$, while maximizing their profit. For amounts larger than $\tilde{\mathcal{E}}$ the fair price of the forest owner is higher than the fair price of the electricity producer. This is consistent with the analytical results (34), (36).

In the following sections we keep all model parameters fixed except for the risk preferences of the forest owner and electricity producer, by assigning values to parameters $\alpha$ and $\beta$, and benefit-sharing ratio $\delta$.

\subsubsection{Sensitivity analysis of fair prices with respect to risk preferences}

In Figure 4 we show, how different values of parameter $\alpha$ (risk preferences of the electricity producer) impact the fair prices of the electricity producer

$p_{E}=p_{E}(\mathcal{E})(30)$ for the fixed benefit-sharing ratio $\delta=0.5$. The range of parameter $\alpha \in[-0.2,0.2]$ corresponds to approximately $10 \%$ variation of 


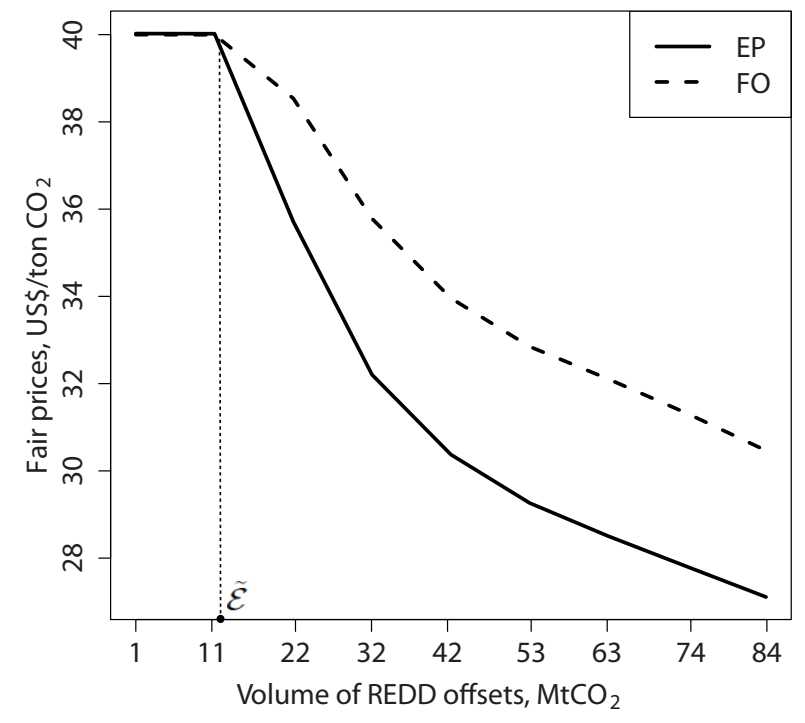

Figure 3: Fair prices of the risk-neutral electricity producer (EP) and forest owner (FO) depending on the volume of REDD offsets. Benefit-sharing ratio is $\delta=0.5$, and future $\mathrm{CO}_{2}$ price distribution is uniform within the range 0-80 US\$/ton $\mathrm{CO}_{2}$.

the fair price relative to the risk-neutral scenario, $\alpha \simeq 0$ (see Figure 1 with utilities). The plot demonstrates, that the risk-taking $(\alpha<0)$ electricity producer is less interested in REDD offsets and, hence, they evaluate these offsets lower than the risk-neutral $(\alpha \simeq 0)$ electricity producer. Quite the opposite, the risk-averse electricity producer $(\alpha>0)$ is ready to pay a higher price for the same amount of REDD offsets.

The sensitivity of a forest owner's fair prices is symmetric to the electricity producer's. The risk-averse forest owner is charging a lower fair price, and the risk-taking - a higher fair price - compared to the risk-neutral behavior. Similar to the electricity producer, the magnitude of change in the forest owner's fair price depends on the degree of risk preference parameter $\beta$.

\subsubsection{Impacts of risk preferences on contracted amounts of REDD offsets}

Here we consider the risk-averse electricity producer and risk-averse forest owner by setting their risk preference parameters to positive values: $\alpha=\beta=$ 0.1 , and also the risk-taking forest owner and risk-taking electricity producer by setting: $\alpha=\beta=-0.1$.

For convenience let us denote the maximum contracted amounts by the symbol: $\mathcal{E}_{Y Z}$, where $Y$ is a risk preference behavior of the electricity producer 


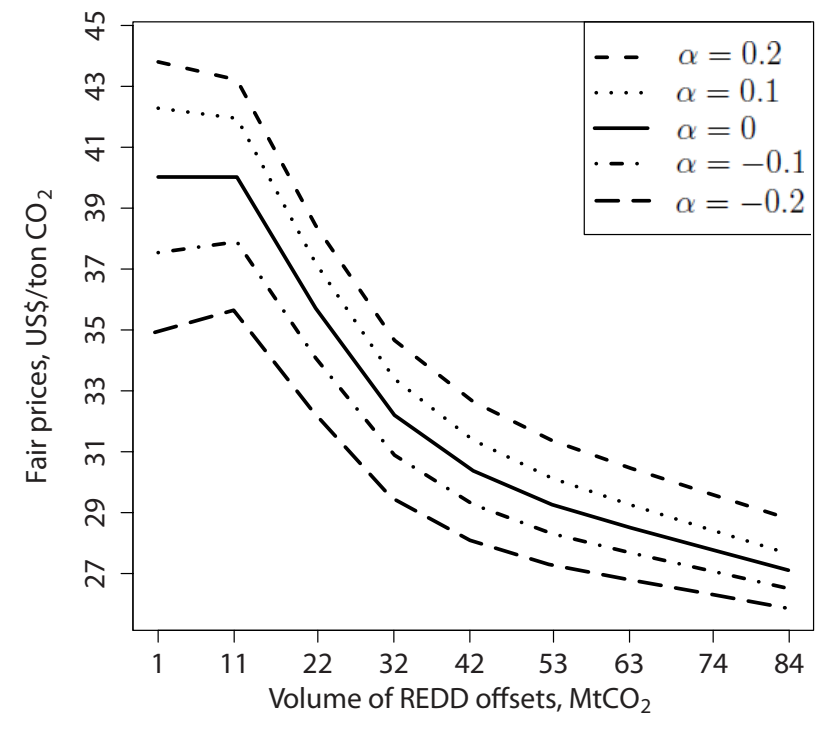

Figure 4: Sensitivity analysis of electricity producer's fair prices with respect to their risk preferences $\alpha<0$ - risk-taking, $\alpha \simeq 0$ - risk-neutral, $\alpha>0$ - risk-averse. Benefit-sharing ratio is $\delta=0.5$.

taking two values: " $a$ " - risk-averse, and " $t$ " - risk-taking, and $Z$ is defined in the same manner for the forest owner.

Figure 5 shows that within the considered set of risk preference parameters the risk aversion of the electricity producer enables contracting the REDD offsets (if EP is risk-taking the fair price curves of EP and FO do not intersect and, hence, there is no agreement on the price and consequently REDD offsets cannot be contracted). The contracted amount when the forest owner is risk-averse exceeds the amount when the forest owner is risk-taking:

$$
\mathcal{E}_{a a}=19.5 \mathrm{MtCO}_{2}>\mathcal{E}_{a t}=15.9 \mathrm{MtCO}_{2} .
$$

Both contracted amounts $\mathcal{E}_{a a}$ and $\mathcal{E}_{a t}$ are greater than in the risk-neutral case (Figure 3). At the same time the risk-taking electricity producer in this experiment never agrees on buying any REDD offsets, $\mathcal{E}_{t a}=\mathcal{E}_{t t}=0$, as their buying price is too low - even lower than than the price set by the risk-averse forest owner (Figure 5). In this case and generally if there is a gap between supply and demand prices, public funds could help close the gap and enable emissions offsetting with REDD.

Modeling results presented in this section highlight, that the risk-averse behavior of the forest owner and electricity producer may lead to an increase 
of contracted amounts of REDD offsets along with a decrease in price (compare Figures 3 and 5). Obviously, the contracted amount of REDD offsets also depends on the benefit-sharing ratio $\delta(\delta=0.5$ here).

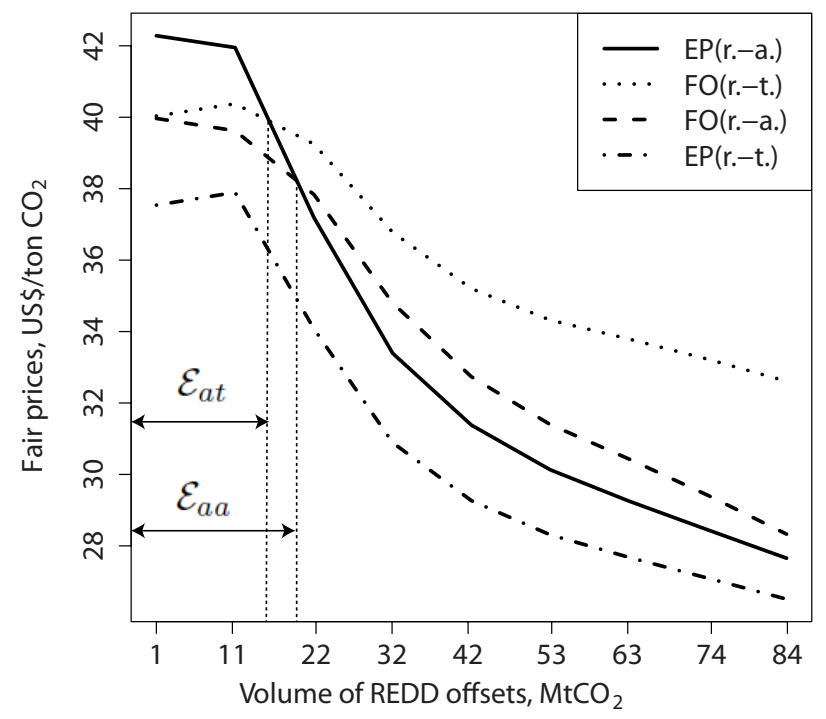

Figure 5: Fair prices of electricity producer (EP) and forest owner (FO) depending on the volume of REDD offsets. Risk-averse (r.-a.) utilities correspond to $\alpha=\beta=0.1$, risk-taking (r.-t.) to $\alpha=\beta=-0.1$. Benefit-sharing ratio is $\delta=0.5$.

\subsubsection{The role of the benefit-sharing mechanism}

We consider a situation of the risk-averse electricity producer and forest owner where parameters are set the following values: $\alpha=0.2, \beta=0.8$. The plot in Figure 6 shows how the benefit-sharing ratio impacts the contracted amounts of REDD offsets. At every value of parameter $\delta$ expected utilities of the forest owner and electricity producer stay the same, but the contracted amounts (solid line) and equilibrium prices (dashed line) differ. The nonlinear shape of the plots is explained by nonregularities in searching for the intersection point between the curves of fair prices (as in Figure 5). Our modeling results indicate that there is a certain value of benefit-sharing ratio, $\delta=0.75$ in our case, which provides the highest possibilities for contracting REDD offsets. Namely, as indicated in Figure 6, at this "optimal" benefit-sharing ratio the entire amount of REDD offsets $83.9 \mathrm{MtCO}_{2}$ can be contracted at the lowest price $32.9 \mathrm{US} \$ /$ ton. In this way, benefit-sharing allows to engage in REDD with less investments at the start. The fact that 
the highest amount can be traded at the lowest price generates possibilities for involving more energy producers in REDD.

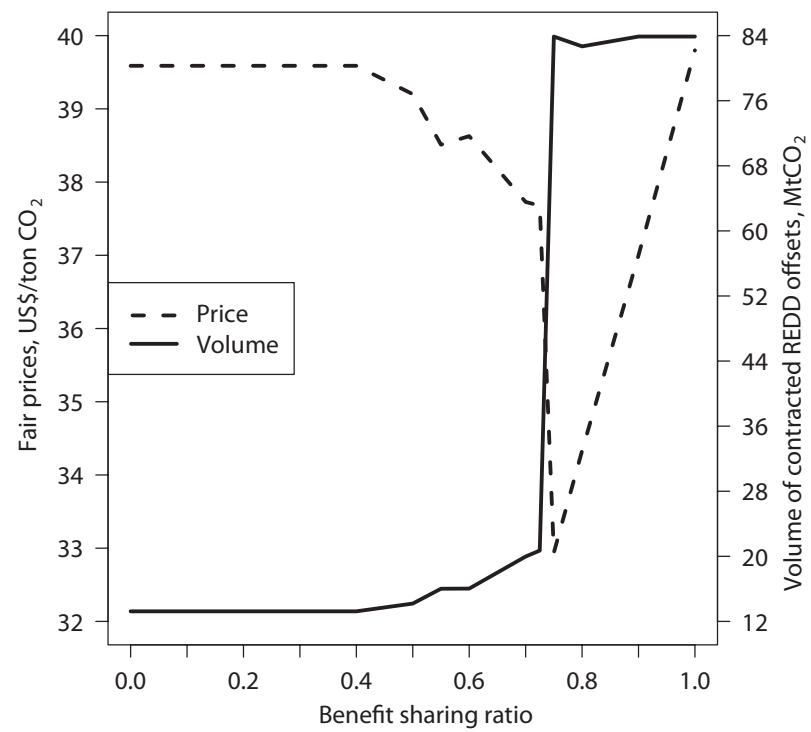

Figure 6: Sensitivity analysis of fair prices and contacted amounts of REDD offsets with respect to benefit-sharing ratio. Forest owner and electricity producer are risk-averse: $\alpha=0.2, \beta=0.08$. Solid line - maximum contracted amounts for each $\delta \in[0,1]$, dashed line - corresponding equilibrium fair prices.

Figure 6 illustrates the following features. Lower benefit-sharing ratios mean that there is no additional profits for electricity producers in the second period (the $\mathrm{CO}_{2}$ price realization). For this reason, the contracts for REDD offsets are at their minimum level (see $\delta$ from 0 to 0.4 ). Namely, the energy producer buys only the minimum amount, which they will use anyway for offsetting. At the same time, the forest owner keeps a higher price for these small amounts, as all of them will be consumed and, therefore, no benefits shared. With the growing sharing ratio, the risk-averse electricity producer gets more flexibility in the uncertain second period; they can exploit high $\mathrm{CO}_{2}$ prices to get additional revenue by selling the unused offsets (despite sharing the benefit with the REDD supplier). Thus, they are willing to buy more offsets. Simultaneously, the REDD supplier knows that they will likely get a benefit share in the second period, and reduces the price. The minimum of the fair price and maximum of the volume is achieved at the ratio $\delta=0.75$. For higher ratios, the electricity producer is still interested in large amounts, 
but the forest owner's share is now too low, and, therefore, they raise the price.

\subsubsection{Multiple ranges of contracted REDD offsets}

In conclusion, we would like to illustrate an interesting effect arising from certain combinations of risk preferences and benefit-sharing ratio. In Figure 7 one can see the fair prices $p_{E}=p_{E}(\mathcal{E})(30)$ and $p_{F}=p_{F}(\mathcal{E})(32)$ constructed for the case when both the electricity producer and forest owner are riskaverse: $\alpha=\beta=0.15$, and benefit-sharing ratio $\delta=0.5$. In the plot we observe two points of intersection, meaning that either smaller amounts of REDD offsets are contracted $\mathcal{E} \leq \mathcal{E}_{a a}$ for the higher price, or a larger amounts $\mathcal{E} \geq \hat{\mathcal{E}}_{a a}$ - at lower prices. At the same time there is a range of amounts of REDD offsets $\mathcal{E} \in\left[\mathcal{E}_{a a}, \hat{\mathcal{E}}_{a a}\right]$, which are not contracted as indicated in Figure 7. In our numerical simulation we observed that this gap vanishes as the benefit-sharing ratio increases.

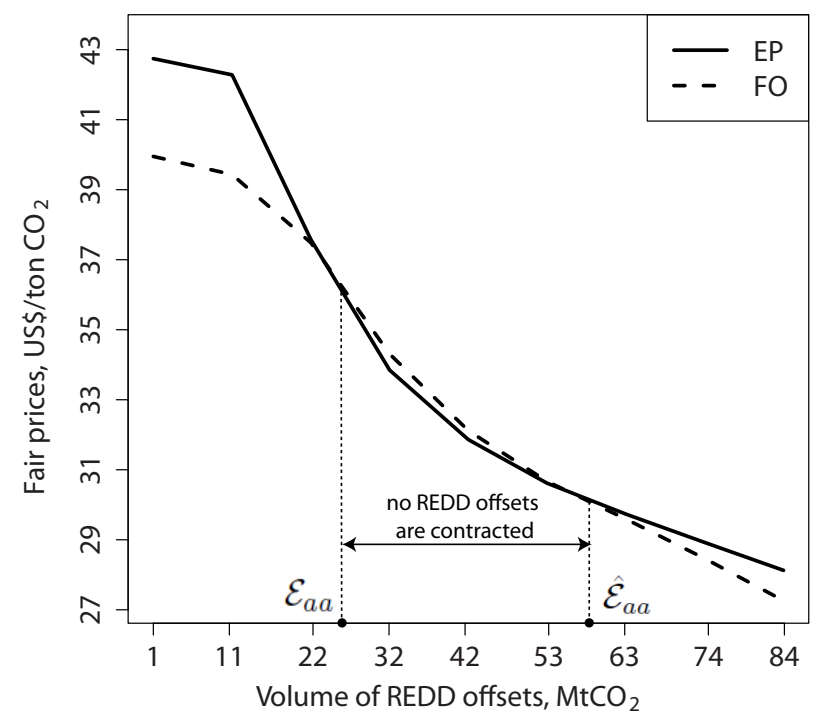

Figure 7: Fair prices of the risk-averse electricity producer (EP), $\alpha=0.15$, and risk-averse forest owner (FO), $\beta=0.15$, for benefit-sharing ratio $\delta=0.5$.

Figure 7 illustrates a bifurcation in a transition from contracting smaller amounts at higher prices to larger amounts at lower prices. The electricity producer is willing to buy smaller amounts when they plan to use them for offsetting, or - larger amounts, when there is a possibility of getting additional profit due to benefit-sharing (financial hedging against high prices). In 
this particular case, intermediate amounts provide additional risks - consuming all of them might be unprofitable, while the volume is not high enough (and the purchase price is not low enough) to get a necessary benefit while sharing. In the figure we see that for range of "intermediate" volumes the forest owner wants a higher price than the electricity producer can offer. This is explained by the fact that they get a higher utility by keeping these volumes and selling them in the second period.

Remark 8. The modeling results presented in this paper deal with a certain range of exponential risk preferences. The analytical results are obtained only for the risk-neutral case. Thus, results may change when different utilities of the forest owner and electricity producer are applied. Studying utilities beyond the exponential class could be an interesting direction for future research.

\section{Conclusions and Policy Implications}

According to a recent IEA (2015) report a considerable share of total $\mathrm{CO}_{2}$ emissions (about $80 \%$ ) comes from the energy sector. This makes the sector a good candidate for emissions reduction and in particular using REDD. In order to implement REDD mechanism efficiently it is necessary to understand the decision-making process (rational behavior) of energy producers - the potential buyers of REDD-based offsets. Our model deals with the medium-term planning of the electricity producer who possesses flexibility in their response to uncertain $\mathrm{CO}_{2}$ prices. The electricity producer in the model is restricted in exercising market power (raising the electricity price) by the elasticity of demand coming from electricity consumers and maximizes their utility (function of profit) by optimizing technological mixes in the production. Utility of the forest owner (REDD supplier) in the model is a function of their profits from selling REDD offsets and reflects their risk preferences. Here we applied an exponential utility function that includes the risk-neutral utility as a special case. The analytical results provided in the paper for the risk-neutral utilities show that there is a restricted amount of REDD offsets that can be contracted in this case. Modeling results on the fair pricing under risk preferences and active benefit-sharing mechanism show that risk-averse behavior increases the contracted amounts compared to the risk-neutral case. In the case where both parties are risk-taking no contracts can be made (for any possible amount of REDD offsets) under symmetric information on $\mathrm{CO}_{2}$ price distribution. We illustrated an important feature of benefit-sharing mechanism, which consists in the possibility 
of choosing optimal benefit-sharing ratio, allowing to contract the highest amount of REDD offsets at the lowest price.

Thus, in this study we identified two promising approaches to effective REDD implementation in connection to the energy sector: (i) strengthening the policy signal to allow for exposing a risk-averse behavior, and (ii) activating the benefit-sharing mechanism. The current delay in REDD implementation can be connected with the fact that energy producers are not able to adequately assess the risks associated with $\mathrm{CO}_{2}$ prices (explained by the weak policy design). An additional hurdle for REDD development is its future acceptance on carbon markets as illustrated by the case of the European Emission Trading System (EU ETS). The benefit-sharing mechanism as discussed in our study, could allow the REDD supplier and consumer to have an alternative means of controlling future uncertainty, and hence facilitate REDD implementation at a larger scale. Another mechanism for supporting REDD (although not cost-free) might involve public funds for closing the price gap between REDD demand and supply, especially when other means are not sufficient and the uncertainty as perceived by the parties still remains too high. This is potentially the case where relatively small investments may play a decisive role in enabling REDD.

Reduction in power generation for the electricity producer is one alternative to REDD. Alternatives to REDD in the longer term which are not considered in the model include for example shifting to greener technologies and/or installing CCS modules (Fuss et al., 2011). EU ETS or similar cap and trade systems, where power generators hold $\mathrm{CO}_{2}$ allowances to hedge for future power sales (see, e.g. Lappi et al. (2010); Schopp and Neuhoff (2013)), are another alternative to REDD. Introducing these alternatives in the model in order to search for trade-off solutions would be an interesting direction for further research.

Acknowledgments. This research received financial support from the project "Options Market and Risk-Reduction Tools for REDD+" funded by the Norwegian Agency for Development Cooperation under agreement number QZA-0464 QZA-13/0074, and was also supported by the EU's Seventh Framework Programme under grant agreement No. 603906 (ECONADAPT). We thank anonymous reviewers for their useful comments and suggestions as well as Matthew Cantele and Cynthia Festin for discussions, reviews, and helpful comments.

Conflict of Interest. The authors declare that they have no conflict of interest. 


\section{References}

Andersen, F., Larsen, H. V., Boomsma, T. K., 2013. Long-term forecasting of hourly electricity load: Identification of consumption profiles and segmentation of customers. Energy Conversion and Management 68, 244-252.

Bigerna, S., Bollino, C. A., 2013. Hourly electricity demand in Italian market. Tech. rep., Università di Perugia, Dipartimento Economia, Finanza e Statistica.

URL http://www.ec.unipg.it/DEFS/uploads/qd_121_web.pdf

Bocquého, G., Jacquet, F., 2010. The adoption of switchgrass and miscanthus by farmers: Impact of liquidity constraints and risk preferences. Energy Policy 38 (5), 2598-2607.

Bohi, D. R., 2013. Analyzing demand behavior: a study of energy elasticities. Routledge.

Fuss, S., Szolgayova, J., Golub, A., Obersteiner, M., 2011. Options on lowcost abatement and investment in the energy sector: new perspectives on REDD. Environment and Development Economics 16 (04), 507-525.

Hunt, L. C., Evans, J., 2009. International handbook on the economics of energy. Edward Elgar Publishing.

IEA, 2015. World energy outlook special report 2015: Energy and climate change. Tech. rep., OECD/IEA.

URL https://www.iea.org/publications/freepublications/publication/WE02015Specia

Janssen, M., Wobben, M., 2009. Electricity pricing and market power - evidence from Germany. European Transactions on Electrical Power 19 (4), 591-611.

Krasovskii, A. A., Khabarov, N. V., Obersteiner, M., 2014. Impacts of the fairly priced REDD-based $\mathrm{CO}_{2}$ offset options on the electricity producers and consumers. Economy of Region (3), 273-288.

Krishnamurthy, C. K. B., Kriström, B., 2015. A cross-country analysis of residential electricity demand in 11 OECD-countries. Resource and Energy Economics 39, 68-88. 
Lappi, P., Ollikka, K., Ollikainen, M., 2010. Optimal fuel-mix in CHP plants under a stochastic permit price: Risk-neutrality versus risk-aversion. Energy Policy 38 (2), 1079-1086.

Lindhjem, H., Aronsen, I., Bråten, K. G., Gleinsvik, A., 2010. Experiences with benefit sharing: issues and options for REDD-plus. Econ Pöyry and Vista report R-2010-018.

URL http://www.lindhjem.info/REDDbenefitsharing.pdf

Lubowski, R. N., Rose, S. K., 2013. The potential for REDD+: Key economic modeling insights and issues. Review of Environmental Economics and Policy 7 (1), 67-90.

Masters, G., 2004. Renewable and efficient electric power systems. WileyInterscience, John Wiley \& Sons, Inc, New Jersey.

Obersteiner, M., Huettner, M., Kraxner, F., McCallum, I., Aoki, K., Bottcher, H., Fritz, S., Gusti, M., Havlik, P., Kindermann, G., et al., 2009. On fair, effective and efficient REDD mechanism design. Carbon Balance and Management 4 (11), 1-11.

OECD, 2009. Mitigating Climate Change in the Context of Incomplete Carbon Pricing Coverage: Issues and Policy Options. OECD Publishing, Ch. 3.

O’Neill, R. P., Hedman, K. W., Krall, E. A., Papavasiliou, A., Oren, S. S., 2010. Economic analysis of the n-1 reliable unit commitment and transmission switching problem using duality concepts. Energy Systems 1 (2), 165-195.

Pratt, J. W., 1964. Risk aversion in the small and in the large. Econometrica: Journal of the Econometric Society, 122-136.

Raiffa, H., 1968. Decision analysis: Introductory lectures on choices under uncertainty. Addison-Wesley.

Schopp, A., Neuhoff, K., 2013. The role of hedging in carbon markets. DIW Discussion Paper 1271.

URL https://www.diw.de/documents/publikationen/73/diw_01.c.416987.de/dp1271.pdf

Schröder, A., Kunz, F., Meiss, J., Mendelevitch, R., Von Hirschhausen, C., 2013. Current and prospective costs of electricity generation until 2050. 
DIW Data Documentation 68.

URL http://www.diw.de/documents/publikationen/73/diw_01.c.424566.de/diw_datadoc_

Stoft, S., 2002. Power System Economics: Designing Markets for Electricity. New York: IEEE Press.

Szolgayová, J., Golub, A., Fuss, S., 2014. Innovation and risk-averse firms: Options on carbon allowances as a hedging tool. Energy Policy 70, 227-235.

Weisser, D., 2007. A guide to life-cycle greenhouse gas (GHG) emissions from electric supply technologies. Energy 32 (9), 1543-1559.

\section{Appendix A. Proof of Lemma 1}

Proof. Firstly, by definition of maximum (8) we have:

$$
\Pi\left(\boldsymbol{x}_{\mathbf{1}}^{*}(p), p\right)=\Pi_{e}\left(\boldsymbol{x}_{\mathbf{1}}^{*}(p)\right)-E\left(\boldsymbol{x}_{\mathbf{1}}^{*}(p)\right) p \geq \Pi_{e}(\boldsymbol{x})-E(\boldsymbol{x}) p .
$$

Secondly, let us assume on the contrary that for some $\overline{\boldsymbol{x}} \in \boldsymbol{X}$, such that $E(\overline{\boldsymbol{x}}) \neq E\left(\boldsymbol{x}_{\mathbf{1}}^{*}(p)\right)$ relation (A.1) is equality. Then, we have:

$$
\hat{\Pi}(p)=\Pi_{e}\left(\boldsymbol{x}_{\mathbf{1}}^{*}(p)\right)-E\left(\boldsymbol{x}_{\mathbf{1}}^{*}(p)\right) p=\Pi_{e}(\overline{\boldsymbol{x}})-E(\overline{\boldsymbol{x}}) p .
$$

According to Remark 2 to Assumption 1 equation (A.2) means that:

$$
\hat{E}(p)=E\left(\boldsymbol{x}_{\mathbf{1}}^{*}(p)\right)=E(\overline{\boldsymbol{x}}) .
$$

Thus, we came to a contradiction, meaning that assumption (A.2) is false, and (11) is true.

\section{Appendix B. Deriving fair prices for some utility functions}

Exponential utility. By substituting exponential utility (18) to (29), we get equation with respect to $p_{E}$ :

$$
\sum_{l=1}^{m} e^{-\alpha \hat{\Pi}\left(p_{l}\right)} w_{l}=\sum_{l=1}^{m} e^{-\alpha\left(\hat{\Pi}^{R}\left(p_{l}\right)-p_{E} \mathcal{E}\right)} w_{l},
$$

which allows for factorizing the term containing the price $p_{E}$ :

$$
\sum_{l=1}^{m} e^{-\alpha \hat{\Pi}\left(p_{l}\right)} w_{l}=e^{\alpha p_{E} \mathcal{E}} \sum_{l=1}^{m} e^{-\alpha \hat{\Pi}^{R}\left(p_{l}\right)} w_{l},
$$

and, consequently, resolve it in the analytical expression (30). 
Logarithmic utility. Let us consider a logarithmic utility function:

$$
U_{E}\left(\Pi_{E}\right)=\ln \Pi_{E} .
$$

Due to monotonicity of logarithmic function, the solution to utility maximization problem at each price $p$ coincides with the solution to profit maximization problem. Therefore for this function we get the following indifference equation (29):

$$
\sum_{l=1}^{m} \ln \left(\hat{\Pi}\left(p_{l}\right)\right) w_{l}=\sum_{l=1}^{m} \ln \left(\hat{\Pi}^{R}\left(p_{l}\right)-p_{E} \mathcal{E}\right) w_{l} .
$$

Here $p_{E}$ can not be factorized and some procedure for deriving it is needed. Risk-neutral utility. Let us derive fair prices for the risk-neutral utilities, which are special cases of exponential utilities. Substituting (28) to the indifference equation (29), we get:

$$
\sum_{l=1}^{m} \hat{\Pi}\left(p_{l}\right) w_{l}=\sum_{l=1}^{m}\left(\hat{\Pi}^{R}\left(p_{l}\right)-p_{E} \mathcal{E}\right) w_{l} .
$$

Here $p_{E}$ can be derived explicitly:

$$
p_{E}=\frac{\sum_{l=1}^{m} \hat{\Pi}^{R}\left(p_{l}\right) w_{l}-\sum_{l=1}^{m} \hat{\Pi}\left(p_{l}\right) w_{l}}{\mathcal{E}} .
$$

In the case of risk-neutral utility, $U_{F}\left(\Pi_{F}\right)=\Pi_{F}$, of the forest owner, we get the following equation with respect to $p_{F}$ :

$$
\sum_{l=1}^{m}\left((1-\delta) p_{l} E^{R}\left(p_{l}\right)+p_{F} \mathcal{E}\right) w_{l}=\sum_{l=1}^{m} p_{l} \mathcal{E} w_{l}
$$

Denoting the mean $\mathrm{CO}_{2}$ price by the symbol $\bar{p}$ :

$$
\bar{p}=\sum_{l=1}^{m} p_{l} w_{l}, \quad \sum_{l=1}^{m} w_{l}=1,
$$

we get:

$$
(1-\delta) \sum_{l=1}^{m} p_{l} E^{R}\left(p_{l}\right) w_{l}+p_{F} \mathcal{E}=\bar{p} \mathcal{E},
$$

leading to the following fair price:

$$
p_{F}=p_{F}(\mathcal{E}, \delta)=\bar{p}-(1-\delta) \frac{\sum_{l=1}^{m} p_{l} E^{R}\left(p_{l}\right) w_{l}}{\mathcal{E}} .
$$




\section{Appendix C. Proof of Theorem 1}

Proof. We represent Problem 2 by two alternative problems.

Problem 2-A. $[E(\boldsymbol{x}) \geq \mathcal{E}]$ Given the feasibility domain $\boldsymbol{X}(6)$ and the amount of REDD offsets $\mathcal{E} \in\left(0, E^{0}\right]$, maximize the profit:

$$
\underset{\boldsymbol{x} \in \boldsymbol{X}_{\boldsymbol{A}}}{\operatorname{maximize}} \Pi_{A}^{R}(\boldsymbol{x}, p),
$$

where

$$
\begin{gathered}
\Pi_{A}^{R}(\boldsymbol{x}, p)=\Pi_{e}(\boldsymbol{x})-p(E(\boldsymbol{x})-\mathcal{E}), \\
\boldsymbol{X}_{\boldsymbol{A}}=\boldsymbol{X} \cap\{\boldsymbol{x}: E(\boldsymbol{x}) \geq \mathcal{E}\} .
\end{gathered}
$$

Let us denote the solution to Problem 2-A by the symbol $\boldsymbol{x}_{\boldsymbol{A}}^{*}=\boldsymbol{x}_{\boldsymbol{A}}^{*}(p) \in$ $\boldsymbol{X}_{\boldsymbol{A}}$. The corresponding maximum profit is given by the relation:

$$
\hat{\Pi}_{A}^{R}=\hat{\Pi}_{A}^{R}(p)=\Pi_{e}\left(\boldsymbol{x}_{\boldsymbol{A}}^{*}\right)-p\left(E\left(\boldsymbol{x}_{\boldsymbol{A}}^{*}\right)-\mathcal{E}\right) .
$$

Problem 2-B. $[E(\boldsymbol{x}) \leq \mathcal{E}]$ Given the feasibility domain $\boldsymbol{X}(6)$, benefitsharing ratio $\delta \in[0,1]$, and the amount of REDD offsets $\mathcal{E} \in\left(0, E^{0}\right]$, maximize the profit:

$$
\underset{\boldsymbol{x} \in \boldsymbol{X}_{\boldsymbol{B}}}{\operatorname{maximize}} \Pi_{B}^{R}(\boldsymbol{x}, p)
$$

where

$$
\begin{gathered}
\Pi_{B}^{R}(\boldsymbol{x}, p)=\Pi_{e}(\boldsymbol{x})-\delta p(E(\boldsymbol{x})-\mathcal{E}), \\
\boldsymbol{X}_{\boldsymbol{B}}=\boldsymbol{X} \cap\{\boldsymbol{x}: E(\boldsymbol{x}) \leq \mathcal{E}\} .
\end{gathered}
$$

Let us denote the solution to Problem 2-B by the symbol $\boldsymbol{x}_{\boldsymbol{B}}^{*}=\boldsymbol{x}_{\boldsymbol{B}}^{*}(p) \in$ $\boldsymbol{X}_{\boldsymbol{B}}$. The corresponding maximum profit is given by the relation:

$$
\hat{\Pi}_{B}^{R}=\hat{\Pi}_{B}^{R}(p)=\Pi_{e}\left(\boldsymbol{x}_{\boldsymbol{B}}^{*}\right)-\delta p\left(E\left(\boldsymbol{x}_{\boldsymbol{B}}^{*}\right)-\mathcal{E}\right) .
$$

Thus, for any fixed amount of $\mathcal{E} \in\left(0, E^{0}\right]$ available in the second period the electricity producer chooses the best response to $\mathrm{CO}_{2}$ price $p=p_{l}$ in terms of profit maximization - between $\hat{\Pi}_{A}^{R}(\mathrm{C} .4)$ and $\hat{\Pi}_{B}^{R}(\mathrm{C} .8)$ :

$$
\hat{\Pi}^{R}(p)=\max \left\{\hat{\Pi}_{A}^{R}, \hat{\Pi}_{B}^{R}\right\},
$$

which is equivalent to (13)-(14). The solution to Problem 2 is chosen according to the rule:

$$
\boldsymbol{x}_{\mathbf{2}}^{*}=\left\{\begin{array}{lll}
\boldsymbol{x}_{\boldsymbol{A}}^{*}, & \text { if } & \hat{\Pi}^{R}=\hat{\Pi}_{A}^{R} \\
\boldsymbol{x}_{\boldsymbol{B}}^{*}, & \text { if } & \hat{\Pi}^{R}=\hat{\Pi}_{B}^{R}
\end{array}\right.
$$


In this section we analytically find the maximum profit (C.9) of the electricity producer depending on the amount of REDD offsets $\mathcal{E} \in\left(0, E^{0}\right]$ and determine the corresponding fair prices of the forest owner and electricity producer. This allows us to obtain an estimate of the amount of REDD offsets that can be contracted in the case of risk-neutral utilities.

We introduce the following function of $\mathrm{CO}_{2}$ price $p$ :

$$
\xi(p)=\frac{\hat{\Pi}^{R}(p)-\hat{\Pi}(p)}{\mathcal{E}} .
$$

Using this function the fair price of the electricity producer (B.6) can be represented as follows:

$$
p_{E}=p_{E}(\mathcal{E}, \delta)=\sum_{l=1}^{M} \xi\left(p_{l}\right) w_{l} .
$$

Similarly, we introduce the function:

$$
\phi(p)=p-(1-\delta) \frac{E^{R}(p) p}{\mathcal{E}},
$$

and represent the forest owner's fair price (B.10) in the following way:

$$
p_{F}=p_{F}(\mathcal{E}, \delta)=\sum_{l=1}^{M} \phi\left(p_{l}\right) w_{l} .
$$

The following lemmas deal with $\mathrm{CO}_{2}$ price realizations $p$. Although these realizations are uncertain, we can analyze optimal responses to any $p$ in terms of decision-making without REDD (Problem 1) and with REDD (Problem 2). This analysis allows us to compare functions $\phi(p)$ and $\xi(p)$ depending on the amount of REDD contracts $\mathcal{E}$ and optimal emissions without REDD, $\hat{E}(p)=E\left(\boldsymbol{x}_{1}^{*}(p)\right)$. Due to the fact that functions (C.11), (C.13) are respective terms in the calculation of fair prices (C.12), (C.14), we can compare $p_{E}$ and $p_{F}$ for a distribution of uncertain prices $\left\{p_{l}, w_{l}\right\}$ (12) according to formulation of the Theorem. Thus, we use the model construction to analytically compare fair prices in the risk-neutral case depending on the amount of REDD offsets.

Lemma 2. For any $\mathrm{CO}_{2}$ price $p$, any benefit-sharing ratio $\delta \in[0,1]$, and any fixed amount $\mathcal{E}$ of contracted offsets in the first period such that $\mathcal{E} \in$ $\left(0, E\left(\boldsymbol{x}_{\mathbf{1}}^{*}(p)\right)\right]$, the equality takes place:

$$
\phi(p)=\xi(p)=p .
$$


The proof is in Appendix C.1

Lemma 3. For any $\mathrm{CO}_{2}$ price $p \in[0, \tilde{p}]$, any benefit-sharing $\delta \in[0,1)$, and any amount $\mathcal{E}$ of contracted offsets in the first period such that $\mathcal{E}>E\left(\boldsymbol{x}_{\mathbf{1}}^{*}(p)\right)$, the inequality takes place:

$$
\phi(p)>\xi(p) .
$$

The proof is in Appendix C.2.

According to Assumption 1 the amount $\tilde{\mathcal{E}}(35)$ is emitted by the electricity producer at any price $p_{l}$ in distribution (12). Hence, for every $p=p_{l}$ in the distribution, the conditions of Lemma 2 are true, meaning that:

$$
\xi(p)=\phi(p)=p
$$

Substituting (C.17) to the definition of fair prices (C.12), (C.14) we get:

$$
p_{E}=\sum_{l=1}^{M} \xi\left(p_{l}\right) w_{l}=\sum_{l=1}^{M} \phi\left(p_{l}\right) w_{l}=\sum_{l=1}^{M} p_{l} w_{l}=\bar{p}=p_{F} .
$$

The same reasoning is valid for any $\mathcal{E} \in(0, \tilde{\mathcal{E}}]$, and, hence, $(34)$ is proved.

For the amount of REDD offsets $\mathcal{E} \in\left(\tilde{\mathcal{E}}, E^{0}\right]$ for some $\mathrm{CO}_{2}$ price realizations $p=p_{l}$ in distribution (12) the conditions of Lemma 2 are satisfied and, hence, $\phi\left(p_{l}\right)=\xi\left(p_{l}\right)$. At the same time, there are price realizations in distribution (12), at which conditions of Lemma 3 are satisfied (at least for the price $\left.\tilde{p}=\max \left\{p_{l}\right\}\right)$, meaning that $\phi\left(p_{l}=\tilde{p}\right)>\xi\left(p_{l}=\tilde{p}\right)$, and hence:

$$
\sum_{l=1}^{M} \phi\left(p_{l}\right) w_{l}>\sum_{l=1}^{M} \xi\left(p_{l}\right) w_{l}
$$

Sustitution of (C.19) to definitions of fair prices (C.12), (C.14) provides the required inequality:

$$
p_{F}=\sum_{l=1}^{M} \phi\left(p_{l}\right) w_{l}>\sum_{l=1}^{M} \xi\left(p_{l}\right) w_{l}=p_{E} .
$$


Appendix C.1. Proof of Lemma 2

Proof. Let us find the optimal profit with REDD in the second period. By the condition of the lemma, $E\left(\boldsymbol{x}_{\mathbf{1}}^{*}(p)\right) \geq \mathcal{E}$, meaning that $\boldsymbol{x}_{\mathbf{1}}^{*}(p) \in \boldsymbol{X}_{\boldsymbol{A}}$ (C.3). It is also true, that $\boldsymbol{X}_{\boldsymbol{A}} \subseteq \boldsymbol{X}$ by definition of $\boldsymbol{X}_{\boldsymbol{A}}$. Problem 2-A (equations (C.1) and (C.2)) is formulated as follows:

$$
\underset{\boldsymbol{x} \in \boldsymbol{X}_{\boldsymbol{A}}}{\operatorname{maximize}}\left\{\Pi_{e}(\boldsymbol{x})-p E(\boldsymbol{x})+p \mathcal{E}\right\} .
$$

Here the term $p \mathcal{E}$ does not depend on $\boldsymbol{x}$, and hence we can solve the following problem:

$$
\underset{\boldsymbol{x} \in \boldsymbol{X}_{\boldsymbol{A}}}{\operatorname{maximize}}\left\{\Pi_{e}(\boldsymbol{x})-p E(\boldsymbol{x})\right\} .
$$

Recall that Problem 1 (equations (7) and (5)) without REDD is:

$$
\underset{\boldsymbol{x} \in \boldsymbol{X}}{\operatorname{maximize}}\left\{\Pi_{e}(\boldsymbol{x})-p E(\boldsymbol{x})\right\} \text {. }
$$

Since $\boldsymbol{x}_{\mathbf{1}}^{*}(p) \in \boldsymbol{X}_{\boldsymbol{A}} \subseteq \boldsymbol{X}, \boldsymbol{x}_{\mathbf{1}}^{*}(p)$ is maximizing both (C.22) and (C.23), implying that their maxima coincide. Using $\hat{\Pi}(p)$ (9) we get the following maximum in Problem 2-A with REDD (C.21):

$$
\hat{\Pi}_{A}^{R}(p)=\Pi_{e}\left(\boldsymbol{x}_{\mathbf{1}}^{*}(p)\right)-E\left(\boldsymbol{x}_{\mathbf{1}}^{*}(p)\right) p+p \mathcal{E}=\hat{\Pi}(p)+p \mathcal{E},
$$

where $\hat{\Pi}(p)$ is the maximum in (C.22) and (C.23).

Let us show that $\hat{\Pi}_{A}^{R} \geq \hat{\Pi}_{B}^{R}$ in (C.9). Indeed, using (C.4), (C.8), (C.24), and the definition of maximum (8), for $\boldsymbol{x}_{\boldsymbol{B}}^{*} \in \boldsymbol{X}_{\boldsymbol{B}} \subseteq \boldsymbol{X}$ we come to the following chain of inequalities:

$$
\begin{aligned}
\hat{\Pi}_{A}^{R}(p)= & \Pi_{e}\left(\boldsymbol{x}_{\boldsymbol{A}}^{*}\right)-p\left(E\left(\boldsymbol{x}_{\boldsymbol{A}}^{*}\right)-\mathcal{E}\right)=\Pi_{e}\left(\boldsymbol{x}_{\mathbf{1}}^{*}(p)\right)-p E\left(\boldsymbol{x}_{\mathbf{1}}^{*}(p)\right)+p \mathcal{E} \geq \\
& \Pi_{e}\left(\boldsymbol{x}_{\boldsymbol{B}}^{*}\right)-p E\left(\boldsymbol{x}_{\boldsymbol{B}}^{*}\right)+p \mathcal{E}=\Pi_{e}\left(\boldsymbol{x}_{\boldsymbol{B}}^{*}\right)-p\left(E\left(\boldsymbol{x}_{\boldsymbol{B}}^{*}\right)-\mathcal{E}\right) \geq \\
& \Pi_{e}\left(\boldsymbol{x}_{\boldsymbol{B}}^{*}\right)-\delta p\left(E\left(\boldsymbol{x}_{\boldsymbol{B}}^{*}\right)-\mathcal{E}\right)=\hat{\Pi}_{B}^{R}(p) .
\end{aligned}
$$

This relation means that $\hat{\Pi}_{A}^{R}(p) \geq \hat{\Pi}_{B}^{R}(p)$ if $\delta=1$, and $\hat{\Pi}_{A}^{R}(p)>\hat{\Pi}_{B}^{R}(p)$ if $\delta \in[0,1)$. Thus,

$$
\hat{\Pi}^{R}(p)=\hat{\Pi}_{A}^{R}(p)=\hat{\Pi}(p)+p \mathcal{E},
$$

meaning that electricity producer uses the whole REDD offsets amount $\mathcal{E}$ and does not share offsets with the forest owner. Substituting $E^{R}(p)=0$ to (C.13) we get:

$$
\phi(p)=p
$$


Substituting (C.26) to (C.11) we get:

$$
\xi(p)=\frac{\hat{\Pi}^{R}(p)-\hat{\Pi}(p)}{\mathcal{E}}=\frac{p \mathcal{E}}{\mathcal{E}}=p .
$$

Appendix C.2. Proof of Lemma 3

Proof. Let us consider two cases depending on the optimal profit in (C.9).

Case 1. $\hat{\Pi}^{R}(p)=\hat{\Pi}_{A}^{R}$, meaning that the electricity producer does not share emission offsets with the forest owner and emits $E\left(\boldsymbol{x}_{\boldsymbol{A}}^{*}(p)\right) \geq \mathcal{E}$. Substituting $E^{R}(p)=0$ to (C.13) we get:

$$
\phi(p)=p .
$$

Substitution of (9) and (C.4) to (C.11) gives the following relation:

$$
\xi(p)=p+\frac{\Pi_{e}\left(\boldsymbol{x}_{\boldsymbol{A}}^{*}(p)\right)-E\left(\boldsymbol{x}_{\boldsymbol{A}}^{*}(p)\right) p}{\mathcal{E}}-\frac{\Pi_{e}\left(\boldsymbol{x}_{\mathbf{1}}^{*}(p)\right)-E\left(\boldsymbol{x}_{\mathbf{1}}^{*}(p)\right) p}{\mathcal{E}} .
$$

For $\boldsymbol{x}_{\boldsymbol{A}}^{*}(p) \in \boldsymbol{X}$ such that $E\left(\boldsymbol{x}_{\boldsymbol{A}}^{*}(p)\right) \geq \mathcal{E}>E\left(\boldsymbol{x}_{\mathbf{1}}^{*}(p)\right)$ we can apply Lemma 1 (11), leading to the following inequality:

$$
\frac{\Pi_{e}\left(\boldsymbol{x}_{\boldsymbol{A}}^{*}(p)\right)-E\left(\boldsymbol{x}_{\boldsymbol{A}}^{*}(p)\right) p}{\mathcal{E}}-\frac{\Pi_{e}\left(\boldsymbol{x}_{\mathbf{1}}^{*}(p)\right)-E\left(\boldsymbol{x}_{\mathbf{1}}^{*}(p)\right) p}{\mathcal{E}}<0 .
$$

Combining (C.29)-(C.31), we obtain the inequality:

$$
\xi(p)<p=\phi(p) .
$$

which proves Case 1.

Case 2. $\hat{\Pi}^{R}(p)=\hat{\Pi}_{B}^{R}$, meaning that the electricity producer can share emission offsets. By analogy with (C.21), (C.22), the solution to Problem 2-B (equations (C.5)-(C.7)) can be obtained by solving the following problem:

$$
\underset{\boldsymbol{x} \in \boldsymbol{X}_{B}}{\operatorname{maximize}}\left\{\Pi_{e}(\boldsymbol{x})-\delta p E(\boldsymbol{x})\right\} .
$$

Thus, two alternatives are possible in Case 2 . 
Case 2a. $\mathcal{E} \geq E\left(\boldsymbol{x}_{\mathbf{1}}^{*}(\delta p)\right)$, meaning that $\boldsymbol{x}_{\mathbf{1}}^{*}(\delta p) \in \boldsymbol{X}_{\boldsymbol{B}}$ (C.7). Problem 1 (equations (7) and (5)) at price $\delta p$ is formulated as follows:

$$
\underset{\boldsymbol{x} \in \boldsymbol{X}}{\operatorname{maximize}}\left\{\Pi_{e}(\boldsymbol{x})-\delta p E(\boldsymbol{x})\right\} .
$$

Since $\boldsymbol{x}_{\mathbf{1}}^{*}(\delta p) \in \boldsymbol{X}_{\boldsymbol{B}} \subseteq \boldsymbol{X}(\mathrm{C} .7), \boldsymbol{x}_{\mathbf{1}}^{*}(\delta p)$ is maximizing both (C.34) and (C.33), implying that their maxima coincide. Using $\hat{\Pi}(\delta p)$ we get the following maximum in Problem 2-B with REDD:

$$
\hat{\Pi}^{R}(p)=\hat{\Pi}_{B}^{R}(p)=\Pi_{e}\left(\boldsymbol{x}_{\mathbf{1}}^{*}(\delta p)\right)-E\left(\boldsymbol{x}_{\mathbf{1}}^{*}(\delta p)\right) \delta p+\delta p \mathcal{E}=\hat{\Pi}(\delta p)+\delta p \mathcal{E} .
$$

Hence, according to Assumption 1 for all $\delta \in[0,1)$ one has:

$$
\hat{E}(\delta p)=E\left(\boldsymbol{x}_{\boldsymbol{B}}^{*}(p)\right)=E\left(\boldsymbol{x}_{\mathbf{1}}^{*}(\delta p)\right)>E\left(\boldsymbol{x}_{\mathbf{1}}^{*}(p)\right) .
$$

Susbtituting $E^{R}(p)=\mathcal{E}-E\left(\boldsymbol{x}_{\boldsymbol{B}}^{*}(p)\right)$ to (C.13) leads to the relation:

$$
\phi(p)=\frac{(1-\delta) p E\left(\boldsymbol{x}_{\boldsymbol{B}}^{*}(p)\right)}{\mathcal{E}}+\delta p .
$$

The function $\xi$ (C.11) takes the form:

$$
\xi(p)=\delta p+\frac{\Pi_{e}\left(\boldsymbol{x}_{\boldsymbol{B}}^{*}(p)\right)-E\left(\boldsymbol{x}_{\boldsymbol{B}}^{*}(p)\right) \delta p}{\mathcal{E}}-\frac{\Pi_{e}\left(\boldsymbol{x}_{\mathbf{1}}^{*}(p)\right)-E\left(\boldsymbol{x}_{\mathbf{1}}^{*}(p)\right) p}{\mathcal{E}} .
$$

For the optimal mix $\boldsymbol{x}_{\boldsymbol{B}}^{*} \in \boldsymbol{X}$ such that (C.36) is true, one can apply Lemma 1:

$$
\Pi_{e}\left(\boldsymbol{x}_{\mathbf{1}}^{*}(p)\right)-E\left(\boldsymbol{x}_{\mathbf{1}}^{*}(p)\right) p>\Pi_{e}\left(\boldsymbol{x}_{\boldsymbol{B}}^{*}(p)\right)-E\left(\boldsymbol{x}_{\boldsymbol{B}}^{*}(p)\right) p .
$$

Substitution of (C.39) to (C.38) gives the required inequality:

$$
\begin{aligned}
\xi(p)= & \delta p+\frac{\Pi_{e}\left(\boldsymbol{x}_{\boldsymbol{B}}^{*}(p)\right)-E\left(\boldsymbol{x}_{\boldsymbol{B}}^{*}(p)\right) \delta p-\left(\Pi_{e}\left(\boldsymbol{x}_{\mathbf{1}}^{*}(p)\right)-E\left(\boldsymbol{x}_{\mathbf{1}}^{*}(p)\right) p\right)}{\mathcal{E}}< \\
& \delta p+\frac{\Pi_{e}\left(\boldsymbol{x}_{\boldsymbol{B}}^{*}(p)\right)-E\left(\boldsymbol{x}_{\boldsymbol{B}}^{*}(p)\right) \delta p-\left(\Pi_{e}\left(\boldsymbol{x}_{\boldsymbol{B}}^{*}(p)\right)-E\left(\boldsymbol{x}_{\boldsymbol{B}}^{*}(p)\right) p\right)}{\mathcal{E}}= \\
& \delta p+\frac{(1-\delta) p E\left(\boldsymbol{x}_{\boldsymbol{B}}^{*}(p)\right)}{\mathcal{E}}=\phi(p) .
\end{aligned}
$$




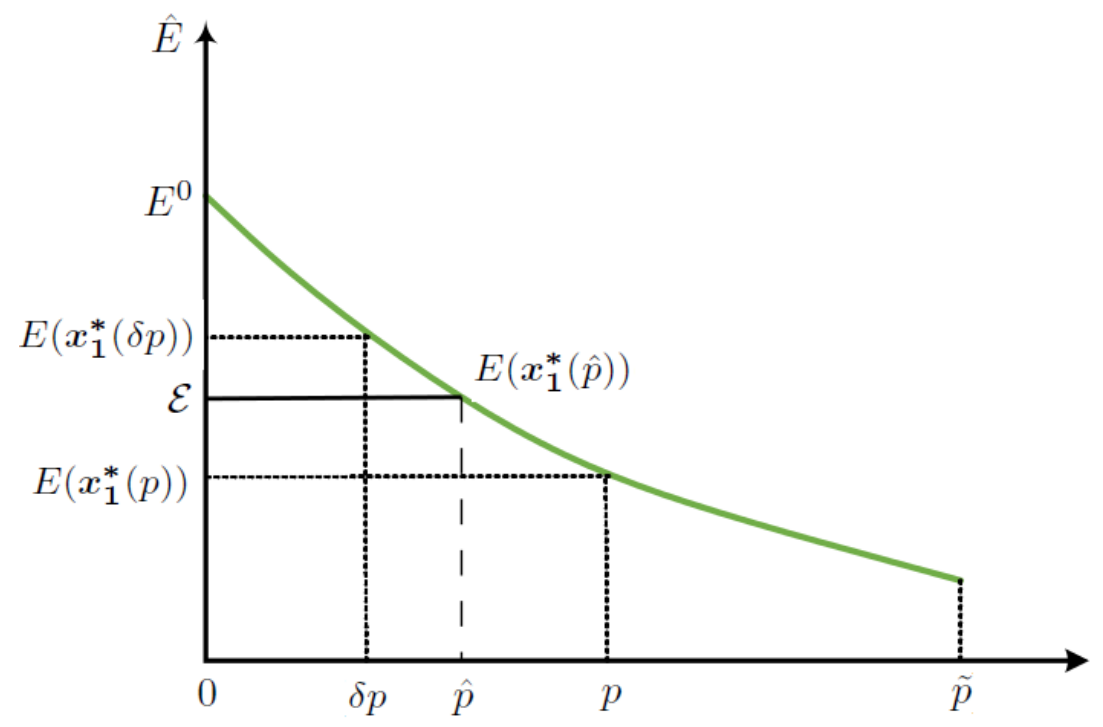

Figure C.8: Optimal emissions of the electricity producer with respect to $\mathrm{CO}_{2}$ price (horizontal axis) without REDD offsets. A conceptual graph of $\hat{E}(p)$, satisfying Assumption 1.

Case 2b. $\mathcal{E}<E\left(\boldsymbol{x}_{1}^{*}(\delta p)\right)$, meaning that $\boldsymbol{x}_{1}^{*}(\delta p) \notin \boldsymbol{X}_{\boldsymbol{B}}$ (C.7). According to Assumption 1 there exist price $\hat{p}, \delta p<\hat{p}<p$, and technological mix $\boldsymbol{x}_{\mathbf{1}}^{*}(\hat{p})$ (see Figure C.8), such that:

$$
\boldsymbol{x}_{1}^{*}(\hat{p}) \in \boldsymbol{X}_{\boldsymbol{B}} \subset \boldsymbol{X}: \quad E\left(\boldsymbol{x}_{\mathbf{1}}^{*}(\hat{p})\right)=\mathcal{E} .
$$

Below we show that technological mix $\boldsymbol{x}_{\boldsymbol{B}}^{*}=\boldsymbol{x}_{\mathbf{1}}^{*}(\hat{p})$ is the solution to Problem 2-B in this case. Let us take a technological mix $\tilde{\boldsymbol{x}}_{\boldsymbol{B}} \in \boldsymbol{X}_{\boldsymbol{B}}$ different from $\boldsymbol{x}_{1}^{*}(\hat{p})$ (C.41). By definition of $\boldsymbol{X}_{\boldsymbol{B}}$ (C.7), $E\left(\tilde{\boldsymbol{x}}_{\boldsymbol{B}}\right) \leq E\left(\boldsymbol{x}_{1}^{*}(\hat{p})\right)=\mathcal{E}$, meaning that the following inequality holds:

$$
E\left(\boldsymbol{x}_{\mathbf{1}}^{*}(\hat{p})\right)(\hat{p}-\delta p) \geq E\left(\tilde{\boldsymbol{x}}_{\boldsymbol{B}}\right)(\hat{p}-\delta p) .
$$

At the same time, by definition of maximum (8) at price $\hat{p}$ we have:

$$
\Pi_{e}\left(\boldsymbol{x}_{\mathbf{1}}^{*}(\hat{p})\right)-E\left(\boldsymbol{x}_{\mathbf{1}}^{*}(\hat{p})\right) \hat{p} \geq \Pi_{e}\left(\tilde{\boldsymbol{x}}_{\boldsymbol{B}}\right)-E\left(\tilde{\boldsymbol{x}}_{\boldsymbol{B}}\right) \hat{p} .
$$

Combining (C.42) and (C.43) one gets:

$$
\begin{array}{r}
\Pi_{e}\left(\boldsymbol{x}_{\mathbf{1}}^{*}(\hat{p})\right)-E\left(\boldsymbol{x}_{\mathbf{1}}^{*}(\hat{p})\right) \hat{p}+E\left(\boldsymbol{x}_{\mathbf{1}}^{*}(\hat{p})\right)(\hat{p}-\delta p) \geq \\
\Pi_{e}\left(\tilde{\boldsymbol{x}}_{\boldsymbol{B}}\right)-E\left(\tilde{\boldsymbol{x}}_{\boldsymbol{B}}\right) \hat{p}+E\left(\tilde{\boldsymbol{x}}_{\boldsymbol{B}}\right)(\hat{p}-\delta p),
\end{array}
$$


that leads to:

$$
\Pi_{e}\left(\boldsymbol{x}_{\mathbf{1}}^{*}(\hat{p})\right)-E\left(\boldsymbol{x}_{\mathbf{1}}^{*}(\hat{p})\right) \delta p \geq \Pi_{e}\left(\tilde{\boldsymbol{x}}_{\boldsymbol{B}}\right)-E\left(\tilde{\boldsymbol{x}}_{\boldsymbol{B}}\right) \delta p \quad \text { for all } \quad \tilde{\boldsymbol{x}}_{\boldsymbol{B}} \in \boldsymbol{X}_{\boldsymbol{B}}
$$

meaning that $\left.\hat{\Pi}_{B}^{R}=\Pi\left(\boldsymbol{x}_{\mathbf{1}}^{*}(\hat{p})\right), \delta p\right)$, and:

$$
E\left(\boldsymbol{x}_{\boldsymbol{B}}^{*}\right)=E\left(\boldsymbol{x}_{\mathbf{1}}^{*}(\hat{p})\right)=\mathcal{E}>E\left(\boldsymbol{x}_{\mathbf{1}}^{*}(p)\right) .
$$

We have proved that in the Case $2 \mathrm{~b}$ the electricity producer does not return any offsets to the forest owner and emits exactly the amount $\mathcal{E}$. Substituting $E^{R}(p)=0$ to $\phi$ (C.13), we get:

$$
\phi(p)=p
$$

Based on (C.46) we can apply Lemma 1, which leads to the following inequality:

$$
\Pi_{e}\left(\boldsymbol{x}_{\mathbf{1}}^{*}(\hat{p})\right)-E\left(\boldsymbol{x}_{\mathbf{1}}^{*}(\hat{p})\right) p<\Pi_{e}\left(\boldsymbol{x}_{\mathbf{1}}^{*}(p)\right)-E\left(\boldsymbol{x}_{\mathbf{1}}^{*}(p)\right) p .
$$

Function $\xi$ (C.11) in this case is calculated as follows:

$$
\begin{aligned}
\xi(p) & =\delta p+\frac{\Pi_{e}\left(\boldsymbol{x}_{\mathbf{1}}^{*}(\hat{p})\right)-E\left(\boldsymbol{x}_{\mathbf{1}}^{*}(\hat{p})\right) \delta p-\left(\Pi_{e}\left(\boldsymbol{x}_{\mathbf{1}}^{*}(p)\right)-E\left(\boldsymbol{x}_{\mathbf{1}}^{*}(p)\right) p\right)}{\mathcal{E}}= \\
& =\delta p+\frac{\Pi_{e}\left(\boldsymbol{x}_{\mathbf{1}}^{*}(\hat{p})\right)-E\left(\boldsymbol{x}_{\mathbf{1}}^{*}(\hat{p})\right) p-\left(\Pi_{e}\left(\boldsymbol{x}_{\mathbf{1}}^{*}(p)\right)-E\left(\boldsymbol{x}_{\mathbf{1}}^{*}(p)\right) p\right)}{\mathcal{E}}+ \\
& +\frac{(1-\delta) p E\left(\boldsymbol{x}_{\mathbf{1}}^{*}(\hat{p})\right)}{\mathcal{E}} .
\end{aligned}
$$

Applying (C.48) and recalling that $E\left(\boldsymbol{x}_{1}^{*}(\hat{p})\right)=\mathcal{E}$ (C.46), we get:

$\xi(p)<\delta p+\frac{(1-\delta) p E\left(\boldsymbol{x}_{1}^{*}(\hat{p})\right)}{\mathcal{E}}=\delta p+\frac{(1-\delta) p \mathcal{E}}{\mathcal{E}}=\delta p+(1-\delta) p=p=\phi(p)$.

Thus, we have proved that in all cases:

$$
\xi(p)<\phi(p) .
$$

